\title{
Hemispheric asymmetries in the ionosphere response observed during the high-speed solar wind streams of the 24-28 August 2010
}

\author{
N. Zaourar ${ }^{(1,2)}$, C. Amory-Mazaudier ${ }^{(2,3)}$ R. Fleury ${ }^{(4)}$
}

1,2 Laboratoire de Géophysique, FSTGAT, B.P.32 USTHB, 16123 Bab-Ezzouar, Alger,Algérie.naimaboulasba@gmail.com

${ }^{2}$ LPP/Polytechnique/UPMC/CNRS, 4 place Jussieu 75005, France,

${ }^{3}$ ICTP, Trieste, Italy

christine.amory@lpp.polytechnique.fr

${ }^{4}$ Lab-STICC, UMR, Mines- Télécom Bretagne CS 83818 Brest cedex 3, France rolland.fleury@telecom-bretagne.eu

\section{AbSTRACT}

This paper presents the geomagnetic and ionospheric responses to a high speed solar wind stream (HSS) impacting the magnetosphere on 24 August 2010. We focus our study on the interhemispheric conjugated behavior. The solar wind speed remained very high during 5 days from 24 to 28 August 2010. By using magnetometer and ground-based GPS data from various approximately conjugated magnetic observatories and GPS stations, we studied the hemispheric asymmetries in the magnetic signature, Vertical Total Electron Content (VTEC) and scintillation activity during this HSS event. Geomagnetic activity reveals larger disturbances in amplitude in the Northern Hemisphere (NH) than in the southern Hemisphere $(\mathrm{SH})$, and stronger asymmetries at higher latitudes, than at lower latitudes, between the conjugate observatories. VTEC variations reveal large increases in amplitude in the NH; while these effects are less pronounced in the SH. We investigate also the GPS scintillation activities occurring in the conjugated polar regions under HSSs conditions. At auroral latitudes, our results show a good correlation between the rate of VTEC index (ROTI) and auroral $\mathrm{Al}$ index, with more intense phase fluctuations in the $\mathrm{NH}$.

Keywords: hemispheric asymmetries, High speed solar wind, Ionosphere, ground magnetic variations, VTEC 


\section{INTRODUCTION}

The response of the Earth's magnetosphere to a high- speed solar wind streams (HSS) offers a particular opportunity to study how the solar wind couples to the magnetosphere- ionosphere (MI) system, on the dayside. The fast solar winds flowing from coronal hole interact with the slow solar wind forming a corotating interaction region (CIR). Such a CIR interacting with the Earth's magnetosphere with a high solar wind speed $(500-1000 \mathrm{~km} / \mathrm{s})$ generates large auroral activity during several days (Grandin et al., 2015). HSSs are considered as important drivers of geomagnetic activity and their effects in the MI system have been reported by several authors (Tsurutani et al., 2006; Denton and Borovsky 2008; Kavanagh and Denton 2007; Huang 2012).

As it is commonly recognized, (Borovsky and Denton, 2006), the HSSs driven disturbances are considerably less strong than those generated by the CME. But, the HSSs include largeamplitude Alfénic waves with southward IMF Bz oscillations (Turner et al., 2009; Kavanagh and Denton 2007). The Alfven waves within HSSs continuously inject energy at high- latitude and lead to extended electrodynamics perturbations (Pedatella and Forbes, 2011). So the total energy input into the MI system tends to be greater during HSSs event than during CME event and the HSSs driven disturbances can affect the MI system on a global scale (Verkhoglyadova et al., 2013).

Following Newell et al., (2007), the HSSs produce magnetic flux merging on the dayside magnetopause and the magnetospheric energy is mainly discharged to the auroral zone by particle precipitation and Joule heating processes. In the auroral zone, Joule heating induces atmospheric disturbances which move to equatorial ionosphere and generate dynamo electric field there. At high-latitudes, the ionospheric convection depends on the IMF strength and orientation (Weimer, 1995). Heelis and Sojka (2011), Pedatella and Forbes (2011), reported that the high-latitudes ionospheric convection shows periodic variations in response to the HSSs.

The prompt penetration electric fields resulting from the transmission of magnetospheric convection electric field from high to low latitudes occurs at the beginning of geomagnetic disturbances when there are large variations of the IMF (Vasyliunas, 1970). The equivalent current system associated to the prompt penetration is named DP2 (Nishida, 1968). The periods of DP2 are on average of the order of minutes to 3hours. During the last decades many experimental and theoretical studies highlighted the characteristics of prompt 
penetration of magnetospheric convection (Fejer et al., 1983; Mazaudier et al., 1984; Spiro et al., 1988; Fejer and Scherliess, 1997; Kobéa et al., 1998, 2000; Peymirat et al., 2000; Mene et al., 2011).

At auroral latitudes, the auroral electrojets currents transfer heat energy to the neutral gas via Joule heating (J.E, J: electric current, E: electric field). In addition, they move the neutral wind via momentum transfer by the Ampere force $\mathrm{JxB}$ (J: electric current, B: magnetic field). The changes in the neutral thermosphere circulation generate electric fields and currents, at the origin the ionospheric disturbance dynamo (Blanc and Richmond, 1980). The ionospheric disturbance dynamo lasts a long time (hours to days). The equivalent current system due to the sole ionospheric disturbance dynamo is named $\mathrm{D}_{\text {dyn }}$ (Le Huy and Amory-Mazaudier, 2005; Fathy et al., 2014))

Existing observations reveal that the ionosphere- thermosphere response to solar wind drivers of the MI system shows asymmetries between the Northern Hemisphere (NH) and the Southern Hemisphere ( $\mathrm{SH}$ ) which contributes to the hemispheric asymmetries. These asymmetries interest essentially the dynamics of high-latitude plasma convection and the neutral in the upper atmosphere. At first, asymmetries of the MI system were initially correlated with interplanetary magnetic field (IMF) orientation, season and ionospheric conductivity in the upper atmosphere (Richmond and Roble, 1987).

The conductivities of solar origin enhanced in summer and diminished in winter depend on the local amplitude of geomagnetic field which is certainly different in conjugated magnetic points (Wagner et al., 1980; Gasda and Richmond, 1998). Asymmetric currents due to different ionospheric conductivities in the dark and sunlit conjugated hemispheres have been established by Benkevich et al., (2000). Some findings in the recent studies of both groundand satellite observations demonstrate that the dynamic in the upper atmosphere shows asymmetrical features in geomagnetic and ionospheric activity (Laundal et al., 2010;Østgaard et al., 2012; Kim et al., 2013, Prikryl et al., 2011).

In addition, interhemispheric similarities and differences result by the ionospheric convection at high latitudes (Cowley et al., 1991). The interhemispheric similarities and asymmetries of ionospheric TEC and scintillation activities during geomagnetic storms at high latitudes were also reported by some studies during the last decades (Cowley et al., 1991; Coster et al., 2006; Prikryl et al. 2011; Prikryl et al., 2015).

In this paper, we focus on the HSSs effects emanating from a transient coronal hole, which are distinguished to be short lived phenomena (hours or days). These coronal holes are 
isolated and have no periodicity. Their occurrence is frequently related with strong eruptions and coronal mass ejections (CMEs) (Storini et al., 2006).

We analyze the response of the ionosphere to HSS event using conjugated magnetic observatories and GPS conjugated stations at various geomagnetic latitudes. Studies in NH and $\mathrm{SH}$ at conjugated magnetic point ground observations are not often investigated, essentially due to the limited observatories with high quality data in $\mathrm{SH}$.We examine hemispheric asymmetries in geomagnetic and ionospheric activity from 20 to 31 August 2010. Section 2 describes the data and data processing. Section 3 presents the methods of analysis, starting with the detailed morphological data description followed by a multi scale wavelet analysis of the ionospheric fluctuations. We discuss the results in section 4. Finally, we conclude with the perspective to develop a statistical analysis focused on HSSs and their effects in the magnetosphere -ionosphere interaction.

\section{DATA SET AND DATA PROCESSING}

\subsection{Data sets}

We analyze the magnetic signature of disturbed ionospheric electric current driven by a high speed solar wind stream (HSS) from 20 to 31 August 2010. This period includes magnetic quiet days before and after the HSS.

To study the ionospheric behavior from 24 to 28 August 2010, we use the following parameters:

1) Solar wind speed $V_{x}$ and $B_{z}$ component of the interplanetary magnetic field recorded on board the satellite ACE (http://omniweb.gsfc.nasa.gov/)

2) The magnetic index Dst, AU, AL and Am are extracted from Data Analysis International Union of Geodesy and Geophysics (IUGG), (http://www.iugg.org/IAGA /). Dst index gives an estimation of magnetospheric currents and depicts the diverse phases of magnetospheric perturbations (Huang et al., 2004). The AU and AL indices give the amplitude of the eastward and westward auroral electrojets. The Am magnetic indices are used to select magnetic quiet days (Mayaud, 1980; Menvielle and Marchaudon, 2008). We select for this study six magnetic quiet days with all the Am $<20$ (in bold in Table 2).

3) Ground data recorded in various latitude geomagnetic conjugated observatories of INTERMAGNET network (www.intermagnet.org/apps/dl data deff.pfp) over the American, 
European and African geomagnetic longitude sectors. Each couple of magnetometers is in the same sector of geomagnetic longitude, at different latitudes in the $\mathrm{NH}$ and $\mathrm{SH}$. Table 1 gives the geographic and corrected geomagnetic coordinates of the magnetic observatories. Figure 1 shows the planetary map of INTERMAGNET observatories.

4) Ground based GPS-receivers (www.igs.org) which geographic and corrected geomagnetic coordinates are also given in Table 1.

\subsection{Data processing}

\section{Magnetic data}

The disturbance horizontal $\mathrm{H}$ component of the Earth' magnetic field is defined by the following relation:

$$
H=\sqrt{X^{2}+Y^{2}}
$$

$\mathrm{X}$ is the north component and $\mathrm{Y}$ the east component of the Earth's magnetic field.

The observed $\Delta \mathrm{H}$ variation integrates the effects of all current systems flowing in the magnetosphere- ionosphere system (Cole, 1966; Fukushima and Kamide, 1973) and can be expressed as:

$\Delta H=S_{R}+D$

$\mathrm{S}_{\mathrm{R}}$ is the daily solar regular variation of the Earth's magnetic field related to the regular ionospheric dynamo driven by the solar heating. The disturbance component $\mathrm{D}$ is the sum of magnetic effects associated to the different current systems flowing in the magnetosphereionosphere system:

$D=D_{\text {iono }}+D_{C F}+D_{R}+D_{T}+D_{G}$

$\mathrm{D}_{\text {iono }}$ is the magnetic disturbance associated to the disturbed ionospheric currents. $\mathrm{D}_{\text {iono }}$ is the sum of two main disturbances: 1) $D_{\text {dyn }}$ due to the storm winds induced by high latitudes Joule heating and ion drag (Blanc and Richmond, 1980; Le Huy and Amory-Mazaudier, 2005) and 2) the prompt penetration of magnetospheric convection electric field (Vasyliunas, 1970 ) at the origin of the DP2 equivalent current system(Nishida, 1968). $D_{C F}$ and $D_{T}$ are the 
Chapman Ferraro currents and the tail currents and are generally ignored. The ring current $D_{R}$ is generally the strongest one, except in the case of HSS event where the DCF is more important. DG design effects of induced currents which comparable variations than the external current; it is a few percentage of Diono (Sabaka et al., 2004).

The symmetric component of the ring current effect $\mathrm{D}_{\mathrm{R}}$ is derived from the Dst index : $D_{R}=$ SYMHcos $(\lambda)$, where $\lambda$ is the colatitude of the observatory. SYMH is the one minute highresolution version of $D s t$ derived using data from magnetic observatories, close enough to the magnetic equator, which are not under the influence of the equatorial electrojet. The mean regular variation $\left\langle S_{R}\right\rangle$ is estimated by the mean arithmetical value of the $\mathrm{H}$ component using the magnetic quiet days listed in Table 2 with daily $\mathrm{Am}<20$.

The observed $\Delta \mathrm{H}$ variation in equation (2) becomes:

$\Delta H=\left\langle S_{R}(H)>+\mathrm{SYMH} \cos (\lambda)+\right.$ Diono

$\mathrm{D}_{\text {iono }}$ combines the effect of $D P 1+D P_{2}+D P_{3}+D P_{4}+D d y n$

$\mathrm{DP}_{1}$ is the equivalent current system linked to substorm event. This current which is on the night side has no effect at middle and low latitudes as there is no conductivity layer on the night side. The other equivalent current systems $\mathrm{DP}_{3}$ and $\mathrm{DP}_{4}$ are confined on the polar cap (Stauning, 2012). Following these considerations Diono is given by:

$D_{\text {iono }}=D P_{2}+D_{d y n}$

By using the standard Fourier Periodogram estimation procedures to $D_{\text {iono }}$, we find that Fourier power spectra follow power law behaviour and this fact leads to the need of multi scale analysis in order to obtain quantitative information related to the short-term dynamics of the geomagnetic fluctuations. Multiscale wavelet analysis, based mainly on the wavelet software implemented by (Zaourar et al., 2013), is applied to $D_{\text {iono }}$ time series to separate the effects of the polar disturbance DP2 equivalent current from the disturbance dynamo $\left(D_{\text {dyn }}\right)$ at pairs of magnetically conjugated observatories.

\section{GPS data}

\section{Vertical Total Electron Content}

Ground-based GPS-receivers are used to obtain ionospheric TEC between a receiver on the ground and a GPS-satellite at an orbital altitude of approximately $22000 \mathrm{~km}$. We apply the 
standard procedure given by Hoffmann-Wellenhof et al., (1992) and Schaer (1999) for processing GPS measurements. We perform the conversion of slant TEC (STEC) data series to absolute Vertical TEC (VTEC) using the single mapping function (Schaer, 1999). TEC is measured in TEC units with 1 tecu $=10^{16}$ electron $/ \mathrm{m}^{-2}$.

The rate of change of TEC index defines the ROT computed in units of tecu/min as follows:

$\mathrm{ROT}=\frac{S T E C_{k+1}-S T E C_{k}}{\text { time }_{k+1}-\text { time }_{k}} * 60$

Where $\mathrm{k}$ is a time during the day between 0 and 86400 and $(\mathrm{k}+1)$ is the time 30 s later. ROTI index is then computed each 30s, taking the standard deviation of ROT (Pi et al., 1997) over a period of $10 \mathrm{~min}$, with a minimum of 10 points:

ROTI $=\sqrt{\left\langle\text { ROT }^{2}\right\rangle-\langle\text { ROT }\rangle^{2}}$

ROTI index is used to detect the scintillation presence in the ionosphere.

\section{DATA ANALYSIS}

\subsection{Morphological analysis}

Figure 2 shows various parameters for period of study from 20 to 31 August 2010. From top to bottom, there are the time variation of solar wind speed $\mathrm{Vx}(\mathrm{km} / \mathrm{s})$ with time resolution of 1 min, the $\mathrm{Bz}$ component of the IMF with time resolution of $1 \mathrm{~min} \mathrm{Bz}(\mathrm{nT})$, the geomagnetic indices Dst (nT) with time resolution of 1 hour and Auroral Electrojets AU, AL (nT) with time resolution of $1 \mathrm{~min}$.

On 24 August 2010, the solar wind component Vx increases from 450 to $700 \mathrm{~km} / \mathrm{s}$ at 03:50 UT when the high speed solar wind hits the magnetosphere. It reaches a maximum value of $728 \mathrm{~km} / \mathrm{s}$ on 24 August 2010 at 08:34 UT and remains very high during 5 days. On 28 August, Vx gradually decreases until the 31 August 2010 and the value of Vx becomes less than $350 \mathrm{~km} / \mathrm{s}$.

On 24 August, the IMP Bz turns southward at around 3:55 UT with the value of $-5.73 \mathrm{nT}$, and reaches the maximum value of $-9.86 \mathrm{nT}$ at 6:56 UT the same day. The southward $\mathrm{Bz}$ component of IMF oscillates during the whole disturbed period from 24 to 28 August with rapid Alfvénic fluctuations for more than 4 days 
On August 23, around 21:00UT the Dst index reaches the value of $50 \mathrm{nT}$, then it decreases and remains relatively low with a minimum value of $-40 \mathrm{nT}$ around 8:00 UT on 24 August 2010. AU and AL indices show large and persistent variations during the HSS event. AL reaches the minimum value of $-953 \mathrm{nT}$ on 25 August at 3:46 UT and AU a maximum value of $435 \mathrm{nT}$ at 06:01UT on 24 August.

Figure 3 and 4 show the variation of the magnetic disturbance Diono (red curves), associated to the disturbed electric ionospheric currents from August 20 to 31, 2010, we plot conjugated pairs of magnetic observatories for various latitudes. Figure 3a includes equatorial stations. The mean regular variation of the horizontal component of the Earth's magnetic field $<\mathrm{S}_{\mathrm{R}}(\mathrm{H})>$ (blue curves) is superimposed to geomagnetic disturbance $\mathrm{D}_{\text {iono }}$.

Figure 3a presents the superposition $D_{\text {iono }}$ with the $\left\langle S_{R}(H)\right\rangle$ for observatories at low latitudes (MBO, AAE,) and equatorial latitudes (HUA). $\left\langle\mathrm{S}_{\mathrm{R}}(\mathrm{H})\right\rangle$ exhibits the well-known regular pattern for equatorial latitudes, marked by a maximum near the local noon for the three observatories. The amplitude of $\left\langle\mathrm{S}_{\mathrm{R}}(\mathrm{H})\right\rangle$ is stronger at HUA, than at MBO and AAE. HUA is the observatory closest to the magnetic equator and it is located in the American sector where the equatorial electrojet is stronger than in the other sectors. There is no $\left\langle\mathrm{S}_{\mathrm{R}}(\mathrm{H})\right\rangle$ current in the night side due to the weakness of conductivities in the dynamo E region. Note that the $\left\langle\mathrm{S}_{\mathrm{R}}(\mathrm{H})\right\rangle$ is positive on the dayside for low and equatorial latitudes at MBO, AAE and HUA. For these three observatories, $D_{\text {iono }}$ displays an irregular pattern with several minima on the dayside, due to HSS from 24 to 28 August 2010. During this perturbation, the time variations of $D_{\text {iono }}$ are the superposition of rapid oscillations of 1 to 3 hours approximately and long periods more than 12 hours. The magnetic disturbance $D_{\text {iono }}$ includes 1) the DP2 equivalent current (rapid oscillations), due to the prompt penetration of magnetospheric convection electric field and 2) the $\mathrm{D}_{\mathrm{dyn}}$ equivalent current (long periods) due to the ionospheric disturbance dynamo. Table $3 \mathrm{a}$ gives the time occurrence of minima and amplitude of minima of the magnetic disturbance $\mathrm{D}_{\text {iono }}$ for low and equatorial latitudes. The strongest decrease in amplitude of $\mathrm{D}_{\text {iono }}$ is clearly observed at HUA as listed in Table $3 \mathrm{a}$.

Figure $3 \mathrm{bis}$ is similar to figure $3 \mathrm{a}$ for a middle latitude conjugated pair of magnetic observatories: KIV and CZT. In all figures, the observatories located in the NH are on the left side and observatories located in the $\mathrm{SH}$ are on the right side.

In the $\mathrm{NH}$, at $\mathrm{KIV}$, the variations of the $\left\langle\mathrm{S}_{\mathrm{R}}(\mathrm{H})\right\rangle$ correspond to an observatory located north the focus of the Sq current system i.e. a negative maximum value around noon. 
In the $\mathrm{SH}$ at $\mathrm{CZT}$, the variations of the $\left\langle\mathrm{S}_{\mathrm{R}}(\mathrm{H})\right\rangle$ exhibit a maximum positive near the local noon, corresponding to an observatory located between the focus and the equator, and we know that the observatory CZT is located below the focus; during the afternoon the Sq current system exhibits a minimum negative corresponding to an observatory located below the focus, as CZT.

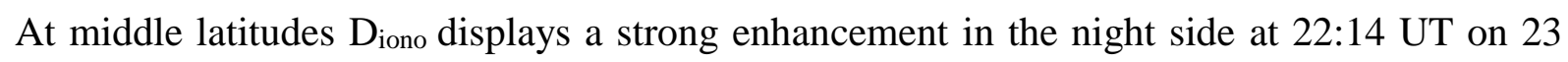
August 2010, followed by southward disturbances at the onset of HSS event on 24 August at 08:34 UT. During the HSS period from 24 to 28 August 2010, $\mathrm{D}_{\text {iono }}$ exhibits several maximum decreases occurring all on the dayside. The DP2 equivalent current is outlined by intense fluctuations superimposed on the $D_{\text {dyn }}$ equivalent current related to the ionospheric disturbance dynamo. Globally, we note higher activity and intense fluctuations at CTZ in SH than at KIV in the NH.

Figure 4 a- c are similar to figure $3 \mathrm{~b}$ for sub-auroral (panels a), auroral (panels b) and polar cap (panels c) latitudes conjugated pairs of observatories. All the curves show mean regular variations of $\left\langle\mathrm{S}_{\mathrm{R}}(\mathrm{H})\right\rangle$ in both hemispheres, characterized by a strong decreasing amplitude at high latitudes, except in RES polar cap $\mathrm{NH}$ where the $\left\langle\mathrm{S}_{\mathrm{R}}(\mathrm{H})\right\rangle$ reveals an amplitude similar to the middle or sub- auroral latitudes response. From 20 to 31 August 2010, D iono presents irregular variations, the strongest appear during the HSS event from 24 to 28 August in both $\mathrm{NH}$ and SH. Table $3 \mathrm{~b}$ summarizes the time occurrence and amplitude of minima of $\mathrm{D}_{\text {iono }}$ at the conjugate points for sub-auroral, auroral and polar cap latitudes.

Figure 4a shows a strong hemispheric asymmetry for the sub auroral latitudes conjugated pair SHU and EYR. On 23 August 2010, we note an augmentation of $D_{\text {iono }}$ that reaches the maximum value of $73.90 \mathrm{nT}$ at 22:13 UT/11:13 LT at SHU and the maximum value of 27.33 nT at 11:15 UT/ 23:15 LT at EYR. During the perturbed period $\mathrm{D}_{\text {iono }}$ presents large southward disturbances characterized by intense oscillations, related to DP2 disturbances, significantly stronger at SHU in the NH than at EYR in the SH.

At auroral latitudes, for the conjugated pairs (BRW and MCQ, ABK and MAW) (Fig. 3b),the amplitude of $\left\langle\mathrm{S}_{\mathrm{R}}(\mathrm{H})\right\rangle$ marks a substantial decrease and oscillates around zero during the studied period.We observe similar hemispheric asymmetry for the conjugated pair BRW and MCQ, marked by more intense southward fluctuations of $\mathrm{D}_{\text {iono }}$ in the NH than in the SH. The disturbed period from 24 to 28 August 2010 is clearly highlighted by a spiky activity generated essentially by DP2 disturbances, stronger in the NH than in the SH. Interestingly, the highest amplitudes of $D_{\text {iono }}$ is marked by five minimum peaks values (Table $3 b$ ) at BRW 
observatory occurring approximately around midnight on 24, 25, 26, 27 and 28 August (see Table 3b). For the conjugated observatory MCQ, similar scenario is observed during the active interval, but $\mathrm{D}_{\text {iono }}$ displays significantly lower minimum values.

For $\mathrm{ABK}$ observatory, $\mathrm{D}_{\text {iono }}$ decreases abruptly reaching several minimum values as noted in Table $3 \mathrm{~b}$. The lowest value of $\mathrm{D}_{\text {iono }}$ is observed around $-272.57 \mathrm{nT}$ at 00:38 UT/01:38 LT on 28 August corresponding to the end of HSS disturbance. Note that the $\mathrm{D}_{\text {iono }}$ fluctuations are more intense at the MAW observatory (Fig. 3b) than at its conjugated observatory ABK (Table 2a).

Figure $4 \mathrm{c}$ shows the superposition of the $\mathrm{D}_{\text {iono }}$ with $\left\langle\mathrm{S}_{\mathrm{R}}(\mathrm{H})\right\rangle$ at the polar cap latitudes for the conjugated pair of observatories RES and SBA. We observe a strong hemispheric asymmetry with opposite effects in the ionospheric response between $\mathrm{NH}$ and $\mathrm{SH}$. $\left\langle\mathrm{S}_{\mathrm{R}}(\mathrm{H})\right\rangle$ provides regular variations, characterized by a higher amplitude at RES in the NH than at SBA in the SH. At RES, $D_{\text {iono }}$ exhibits strong northward excursions on 23 August followed by southward spiky variations, during the night and a northward continuum activity from 24 to 28 August 2010. Inversely, at SBA in SH, Diono presents globally intense northward spiky activity (see Table 3b), during the same period.

\subsection{Wavelet Analysis}

The results of the Fourier analysis of the magnetic disturbance $D_{\text {iono }}$ are summarized in Figure 5 and the characteristic periods in table 4 . All spectra fit a power law as $\mathrm{f}^{-\beta} \quad$ (f: frequency, $B$ : spectral exponent) with a scaling exponent $1<\beta<3$. Power law is a typical characteristic of self-affine time series (Zaourar et al., 2013).

Figure 5 clearly shows the $24 \mathrm{~h}$ period together with three other periods close $2.4 \mathrm{~min}, 45 \mathrm{~min}$ and $14 \mathrm{~min}$. These results motivate the use of multiscale analysis based on continuous wavelet transform (CWT).

Figures 6-7 show the scalograms obtained with the CWT for the conjugated pairs of observatories, from low to high latitudes. All scalograms exhibit the amplitude distribution of the wavelet coefficients in the time-frequency plane. We note that disturbance period from 24 to 28 August 2010 is characterized by higher wavelet coefficients. Indeed, when geomagnetic disturbances are under development, the equivalent current $\mathrm{D}_{\text {iono }}$ can be described by very roughness signals, and consequently the amplitude of wavelet coefficients is considerably large. Clearly, when the magnetosphere- ionosphere system are under quiet conditions, wavelet coefficients display a low amplitude as it is illustrated by figures 6- 7. Further, one 
can observe that the magnetic observations picture different patterns. This behavior may be associated to differences in the magnetic coordinates, local time, ground conductivity and currents effects. All panels indicate the existence of two different regimes in the $\mathrm{D}_{\text {iono }}$ current based on their periodicities, during the HSS event. The first one corresponds to the large amplitude wavelet coefficients at low frequency during the active period from 24 to 28 August 2010, related to the signature of the $D_{\text {dyn }}$ equivalent current. For all the panels the dominant period of the $\mathrm{D}_{\mathrm{dyn}}$ is approximately between 19:00 $\mathrm{h}$ and 24:00 $\mathrm{h}$. The second one corresponds to short term fluctuations DP2 of about $2.4 \mathrm{~h}$ periods during prompt penetration of magnetospheric electric field.

Scalograms in figure $6 \mathrm{a}$ reveal that the $\mathrm{D}_{\text {dyn }}$ disturbance and the magnetic disturbance DP2 show a weak disturbance at the equatorial latitude (HUA and AAE) with a substantial amplification at the magnetic equator (HUA). The amplitude of the DP2 appears higher than the $D_{\text {dyn }}$ over the American sector than over the African sector. At low latitudes, figure $6 \mathrm{~b}$ shows an increase of the amplitude and duration of both disturbances $\mathrm{D}_{\mathrm{dyn}}$ and DP2 at the observatory of MBO during the perturbed period.

At middle latitudes (Fig. 6c), a significant asymmetry is observed with a more pronounced disturbance $\mathrm{D}_{\mathrm{dyn}}$ in term of duration at CZT observatory in the SH than at KIV observatory in the NH.

The shape of $\mathrm{D}_{\text {iono }}$ variations in figure 7 features the dynamics of the time series complexity close to the direct penetration of the magnetospheric convection electric field at the origin of intense fluctuations DP2 equivalent current. These observations fully agree with $\mathrm{D}_{\text {iono }}$ curves in figure 4.

Indeed, figure 7 shows that for higher latitudes conjugated pairs observatories (sub-auroral, auroral and polar cap), we observe a larger amplitude of wavelet coefficients at high frequency (enhanced by the red color) during the active period. Short term fluctuations related to DP2 disturbances are recognized by their periodicity with value between $36 \min <\mathrm{T}<1.5 \mathrm{~h}$. Both $\mathrm{D}_{\text {dyn }}$ and DP2 disturbances are more pronounced in the $\mathrm{NH}$ than in the SH revealing a significant hemispheric asymmetry.

The amplitude of $\mathrm{D}_{\text {dyn }}$ is markedly highest in NH (SHU, BRW, ABK and RES) than in SH observatories (EYR, MCQ, MAW and SBA).

Largest amplitude of $\mathrm{D}_{\mathrm{dyn}}$ disturbances lasting 3days is observed at auroral (ABK) and polar cap (RES) observatories in the $\mathrm{NH}$ as showed in the figure $7 \mathrm{~b}-\mathrm{c}$. 


\subsection{GPS ANALYSIS}

This part investigates similarities and differences of VTEC and ionospheric scintillations under HSS conditions at approximately conjugate points over the high and middle latitudes. Ionospheric effects are usually described by measuring their impact on the amplitude and phase of the received GPS signal. The average $\triangle$ VTEC of 24 August 2010 between 09LTand 15LT is estimated relatively to the VTEC observed between 20 and 23 August to examine the spatial distribution of the ionosphere changes in response to HSS at various latitudes. The results show a rather weak difference, so in the figure 8 we have chosen to divide the level of the average $\triangle \mathrm{VTEC}$ in 3 classes: $\triangle \mathrm{VTEC}<0$ tecu (blue square), $\triangle \mathrm{VTEC}>3$ tecu (black square) and transition class (red square).

On the map of figure 8 , the two dotted curves represent the modified magnetic dip (i.e. the Rawer latitudes used to model the F2 region of the ionosphere) $60 \mathrm{~N}$ and $60 \mathrm{~S}$. During magnetically quiet periods, these curves give approximate boundaries between the high and middle latitudes. During disturbed periods, these curves shift to the middle latitudes, and the stronger is the storm the larger is the shift. Therefore, the GPS stations which are very close to these curves (less than 4 to 5 degrees) are assigned to the sub-auroral zone. These positions are in middle latitudes during quiet periods and auroral regions during disturbed periods. Above the curves, in the range of $4 / 5$ degrees, is located the auroral zone and above it until the poles, are the polar stations.

In Figure 8, the middle and lower latitude stations (LAMP-USUD for NH and SANT- SUTM, DARM for SH) are in black squares, which reflects a strong positive effect regardless of the hemisphere. In high latitudes, we remark red squares for polar latitudes in $\mathrm{NH}$ and this for all latitudes for longitudes between $-100 \mathrm{E}$ and 50E (except TRO1 in Europe) corresponding to the local night and morning hours. Black squares appear at auroral latitudes stations in SH at longitudes between $-180 \mathrm{E}$ and $-120 \mathrm{E}$, this corresponds to local late afternoon and early night hours.

In the American sector, a stronger trend is visible at sub auroral (AB07) and auroral (BRW1, HOLM) stations.

In the $\mathrm{SH}$, a strong positive reaction of $\triangle \mathrm{VTEC}$ is observed at subauroral (HOB2, MQZG) and auroral 491(MAC1, KERG) latitudes stations. Even polar (MCM4) and auroral (SYOG and OHI2) stations have a positive deviation of $\triangle \mathrm{VTEC}$ rather lower. 
In order to examine conjugated effects of the VTEC fluctuations activity under HSS conditions, we used data of conjugated pairs stations located in the polar cap, auroral, sub auroral and middle latitudes presented in figure 1 and (Table 1 with an *).

Figure 9 outlines the VTEC changes for the conjugated latitudes pairs stations 20 to 31 August 2014, at all latitudes. At Polar cap latitudes (RESO-MCM4), (Fig. 9a), no significant changes in the VTEC variations due to the impact of the HSS event is detected in both hemispheres.

In figure $9 \mathrm{~b}$ at auroral latitudes (BRW1-MAC1, TRO1-SYOGandJOEN-KERG) and figure 9c at sub auroral latitudes (AB07-MQZG), we observe an asymmetric behavior between $\mathrm{NH}$ and $\mathrm{SH}$, due to the daylight increase of the ionization, that lasts longer about 4 days in the $\mathrm{NH}$.

As expected strong enhanced VTEC is observed (Fig. 9d) at both middle (LAMP-SUTM) conjugate pair stations. Higher amplitude of the VTEC is detected at LAMP station than at SUTM station. At LAMP, the VTEC amplitude goes from an average of 17 to 31 tecu on August 24 , therefore an increase of $+88 \%$, whereas at SUTM on the same period, it goes from an average of 15 to 20 tecu, therefore an increase of only $+33 \%$. Indeed, at this particular position in middle latitudes, a significant asymmetry (of about +11 tecu) is observed between the $\mathrm{NH}$ and $\mathrm{SH}$, during the first day of the storm.

Figure 10 shows the superposition of temporal variations of the ROTI index at conjugated pairs stations. A continuum of changes in the ROTI index between $1-1.5$ tecu/min on which is superimposed numerous peaks of higher intensity ( 2 tecu/min) are seen at the polar cap (RESO-MCM4) conjugated pairs stations (Fig. 10a). Interhemispheric asymmetric behavior is detected revealing a higher activity in the $\mathrm{SH}$.

At auroral conjugated pair station (BRW1-MAC1, TRO1-SYOG), before the arrival of the disturbance, a regular peak is observed around 20UT indicating that stations are in the auroral zone during this time interval. From 24 to 28August 2010, the ROTI index increases strongly reaching values of 4 to 5 tecu /min (Fig.10b) at BRW1 in the NH and values around 3 tecu/min at MAC1 in the SH, highlighting hemispheric asymmetry in the scintillation occurrence. On the other hand, the conjugated stations (TRO1-SYOG) show a similar behavior of the ROTI index. Temporal areas of the ROTI index cover the period from 18UT until 03UT the next day. At (JOEN-KERG) stations, the ROTI index varies like noise, over a range of very low values less than 1 tecu/min (Fig. 10b), except for the day of August 24, corresponding to the arrival of the solar wind disturbance, characterized by a peak of activity slightly higher in the NH than in $\mathrm{SH}$. 
At sub auroral latitudes, conjugated pair stations (AB07-MQZG) display similar behavior in NH and SH (Fig. 10c ) and confirm limited movement, due to very low values observed on the ROTI index.

\section{RESUlTS AND DISCUSSION}

The analysis presented in the previous section demonstrates that geomagnetic activity driven by HSS from 24 to 28 August 2010 induces sufficiently strong and interesting ionospheric effects, at all latitudes. Using ground magnetic data, we observe (Fig. 3-4) the magnetic disturbance $\mathrm{D}_{\text {iono }}$, due to disturbed ionospheric electric currents, opposite to the mean regular one $\left\langle S_{R}(H)\right\rangle$. The magnetic disturbance $D_{\text {iono }}$ results of the electrodynamics coupling between the high and low latitude. $\mathrm{D}_{\text {iono }}$ combines the short term magnetic fluctuations DP2 related to the prompt penetration of magnetospheric convection electric (Nishida, 1968), first modeled by Vasyliunas (1970) and approximately diurnal magnetic fluctuations $D_{\mathrm{dyn}}$, first predicted by Blanc an Richmond (1980), and isolated by Le Huy and Amory-Mazaudier (2005). To further illustrate the main characteristics of the magnetic disturbances $D_{\text {dyn }}$ and DP2 we perform a spectral analysis. Using the classical spectrum, the interesting finding here is the superimposition of some mechanisms driven by physical process, occurring at scales ranging from the minutes (current lower data resolution) to the day (see Fig. 5). This observation constitutes the motivation for describing the $\mathrm{D}_{\text {iono }}$ fluctuations by a wavelet analysis.

The various results observed can be summarized for the different regions:

\section{- At equatorial and low latitudes}

$D_{\text {iono }}$ is southward, related to a westward current of the equatorial electrojet current as reported by Richmond et al., (2003); Zaka et al.,(2009). The $\mathrm{D}_{\text {iono }}$ disturbance is more intense at HUA than at $\mathrm{AAE}$ and $\mathrm{MBO}$, the closest observatory to the magnetic equator with several minima on the dayside, induced by the large daytime Cowling conductivity at the equatorial latitudes. Wavelet analysis allows locating the diverse ionospheric signatures. The first minimum outlined by large amplitude at low frequency represents the signature of the $D_{\text {dyn }}$ equivalent current system (Fig. $6 b$ ). Note that the $\mathrm{D}_{\text {dyn }}$ remains present during the whole perturbed period, 4 days in the African sector (MBO) and 2 days in American sector (HUA), (Fig. 6b), with very low amplitude, at the limit of the detection. Such characteristics can be attributed to their dependence with longitude sector. These observations are in good agreement with Fathy et al., (2014). The second regime is related to the DP2 equivalent current recognizable by its 
fluctuations of about $2.4 \mathrm{~h}$ periods, in the two longitude sectors. The strongest amplitude of DP2 caused by the penetration of convection electric field is observed at the equator (HUA). The DP2 intensifies the equatorial electrojet (Kikuchi and Hashimoto, 2016).

\section{- At middle latitudes}

At middle latitudes conjugated pairs of observatories (Fig. 3b); $D_{\text {iono }}$ is marked by amplification of short term fluctuations and exhibits southward gradual decrease during HSS event. These observations are probably associated with the long duration of auroral activity induced by HSS event. As a consequence, a westward current generated by the disturbance dynamo is produced toward the middle latitude in agreement with Blanc and Richmond, (1980). Wavelet analysis in figure 6c highlights some relevant features in term of asymmetry. The $\mathrm{D}_{\text {dyn }}$ lasts longer (5 days) at CZT in the $\mathrm{SH}$ (Fig. $6 \mathrm{~b}$ right), than at KIV (3 days) in the NH (Fig. 6b left). These results are in agreement with Zaka et al., (2009) who found a hemispheric asymmetry in the ionospheric disturbance dynamo generated by the $D_{\text {dyn }}$ disturbance.

Figure 9d, highlights large increase of VTEC lasting during the HSS event in the NH, whereas in the $\mathrm{SH}$ weaker effect is observed.

Our results reveal also the effects of the penetration of magnetospheric electric fields into the middle latitudes, controlled by the IMF Bz according to previous studies. Indeed, Buresova et al., (2014) carried out a global overview of the ionospheric response to CIR/HSS for middle latitudes using digisondes. They found that long lasting fluctuations in the IMF Bz and large changes in auroral electrojet index induce a significant increase of foF2 and therefore of electron density. However, in contrast to Buresova et al., (2014), a significant asymmetry (of about 11 tecu/min) is observed between the NH and SH (see Figure 9d). These observations are probably associated with the solar wind speed which remains very high speed during 5 days from 24 to 28 August 2010. Furthermore, Huang et al., (2002) established that the solar wind can characterize a very important source of middle ionospheric perturbation.

\section{- At sub auroral latitudes}

A notable asymmetry in geomagnetic response to HSS event is observed at conjugate pair observatories located in sub auroral latitudes ( Fig. 4a). We observe a largest amplitude in the NH than in the SH (see table 3b), during the disturbed period. Østgaard et al., (2005) and $\varnothing$ stgaard et al., (2012) found that for a given event, local ionospheric conditions can induce significant North-South asymmetries, even in the absence of asymmetry in the external driver. 
The $\mathrm{D}_{\text {iono }}$ disturbance is southward and associated with the westward electrojet as reflected by the maximum intensity of AL index (Davis and Sugiura, 1966) in figure 2 bottom. Diono disturbance displays also a significant enhancement of short term fluctuations DP2 associated to the magnetospheric convection electric field. These observations can be interpreted as the effect of enhanced magnetospheric convection which persists during 5 days, typically related to HSS as described by Denton et al., (2009); Verkhoglyadova et al., (2013).

Note that the Bz component of the IMF shows a rapid oscillations during 5 days, related to the Alfvénic structures inducing an intermittent reconnection during the whole disturbed period according to the study of (Tsurutani et al., 2006). Following Kavanagh and Denton (2007). This suggests that unbalanced reconnection takes place over a sufficient period and leads to energy input in the magnetosphere- ionosphere-thermosphere during HSS driven disturbances. The HSS energy input is comparable to or still larger than the energy input during a CME driven storm (Borovsky and Denton, 2006; Turner et al., 2009, ).As reported by Tsurutani et al., (2004), the prolonged interval of Alfvénic IMF Bz due to HSSs leads to continuous auroral zone activity called High-Intensity-Longue-Duration Continuous AE Activity (HILDCAAs).

Furthermore, the time duration and the amplitude of the long time periods $D_{\text {dyn }}$ reveal also hemispheric asymmetry (Fig. 7a). The amplitude of $\mathrm{D}_{\text {dyn }}$ is notably highest in NH (SHU) than in SH (EYR) observatories. These observations are consistent with Mayaud (1970) founding that the $\mathrm{NH}$ is always most disturbed than the $\mathrm{SH}(10 \%)$.

On the contrary, VTEC and ROTI index (Fig. 9-10c) are relatively disturbed with sometimes asymmetries response in conjugated points.

\section{- At auroral latitudes}

The impact of the HSS on the geomagnetic disturbances is the most pronounced at these latitudes (Fig.4b) compared to other latitudes, because most of the time these observatories are connected to the Earth's plasma sheet. Indeed, the strongest currents occurring in the auroral latitudes are induced both by strong heating and higher density in the plasma sheet and enhanced particle precipitation in the auroral regions during HSS (Denton and Borovsky, 2009). Conjugated observatories pairs at auroral latitudes (BRWand MCQ, ABK and MAW) (Fig. 7b) show similar hemispheric asymmetry behavior than at sub auroral latitudes (Fig. 7a), from 24 to 28 August 2010. These differences can be explained by asymmetries in the Earth's magnetic field. Indeed, numerical simulations (Cnossen and Richmond, 2012) support the 
idea that both the strength and the orientation of Earth's magnetic field can influence the solar wind magnetosphere coupling, and thereby affect the ionosphere-thermosphere system. In addition, the magnetic field configuration influences ionospheric conductivity and plasma transport.

Ground GPS data did not show significant enhancement of ionospheric VTEC (Fig. 9b), while the ROTI index (Fig.10b) indicates a large dayside enhancement revealing strong ionospheric scintillations occurrence corresponding to the period of HSSs. We can note similarities (TROT1-SYOG) and asymmetries (BRW1-MACland JOEN-KERG) between the ionospheric response at the conjugated pairs stations accordingly with Prikryl et al., (2014). The different level of the amplitude scintillations is probably caused by higher precipitation in the summer $\mathrm{NH}$. These observations seem to indicate the extension of the auroral zone to the equator. Sub auroral (AB07-MQZG) conjugated pair stations of the figure 10c display similar behavior in $\mathrm{NH}$ and $\mathrm{SH}$ and confirm limited movement, due to very low values showed by the ROTI index. The boundary extension occurs on 2 station positions JOEN and KERG on 24 August 2010.

\section{- At polar cap latitude}

Our observations reveal quite notable asymmetry in geomagnetic response to HSS event (Fig. 4c) between the conjugated points, illustrated by opposite effect in the ionospheric response. High-latitude modeling efforts (Richmond and Roble (1987), Benkevich et al., 2000) support that the hemispheric asymmetry is caused by interhemispheric field-aligned currents (FACs) and their resulting ionospheric currents (i.e., Pedersen and Hall currents) Precisely, Benkevich and Lyatsky, (2000) shown that vortices in equivalent current detached from sources of electric potential may arise on the dayside winter SH and no such vortices can be observed in the summer NH. Asymmetric currents due to different ionospheric conductivities in the dark and sunlit conjugated hemispheres have been established by Benkevich et al., (2000).

Furthermore both conjugated points respond to HSS event through an interhemispheric FACs. The FACs can produce local Hall current system and due to different geomagnetic field mapping between conjugated points produce asymmetry. The wavelet analysis (figure 7c) illustrates the long lasting diurnal and short times periods, with greater amplitude in the $\mathrm{NH}$ than in the SH.

Our results are consistent with observations reported by Laundal et al., (2010), on interhemispheric asymmetries caused by large seasonal differences between the hemispheres, indeed the summer hemisphere responds more promptly to changes in magnetospheric convection than the winter hemisphere. 
Figure 10a shows that a more pronounced scintillation activity is observed at MCM4 southern station than at RESO northern station. The continuum of energy induced by ionospheric irregularities is embedded in polar patches motion of plasma across the polar cap (Prikryl et al., 2014). The spiky activities coinciding with the disturbed period driven by HSS, could be caused by particles precipitation related to the importance of coupling between the southward IMF Bz of the solar wind and the magnetosphere during Alfvenic fluctuations (Denton et al., 2009).

\section{CONCLUSION}

In this paper, we have studied geomagnetic and ionospheric response to the high speed solar wind streams of 24-28 August 2010 using various latitude geomagnetic conjugated observatories determined by the IGRF model and GPS conjugated stations.

This case presents a very simple morphology. The four days before the arrival of the fast wind, from the 20 to 23 August, are magnetically quiet days. The three days after this fast wind, from the 29 to 31 August, are also magnetically quiet days. The ionospheric effect of the fast wind is easily isolated.

Numerous authors focus to link HSSs and electrodynamics of the ionosphere to recurrent activity, our purpose is to show that the geomagnetic activity driven by HSS induces sufficiently strong and interesting ionospheric effects at all latitudes, particularly in term of asymmetries. The strongest geomagnetic and ionospheric activity coincides with the HSS period. By using the wavelet analysis, we observed the presence of short time fluctuations (15min to $1.5 \mathrm{~h}$ ) simultaneously at all latitudes related to the penetration of the magnetospheric convection electric field. The magnetic signature of this electric field is the DP2 equivalent current system. We observed also long time fluctuations (19h to $24 \mathrm{~h}$ ) associated to the ionospheric disturbance dynamo. The magnetic signature of this physical process is the $D_{\text {dyn }}$ equivalent current system

As expected, we notice that the amplitude of the perturbations vary with the latitude. There is a gradual decay in magnetic disturbance towards lower latitudes, while an increasing ionospheric VTEC is observed towards middle latitude. The strongest variations of the magnetic and ionospheric phase scintillation are observed at auroral latitudes. This behavior is consistent with enhanced particles precipitation in the auroral zone.

These observations are related to a direct ionization effect by electron precipitation in the sector night (before midnight) which leads to a significant increase in VTEC in auroral 
stations. For the dayside stations, the VTEC increases more slowly. The same behavior is detected for various stations in the $\mathrm{NH}$ and inOHI2 station in the $\mathrm{SH}$.

The interhemispheric response at conjugated latitudes pairs appears different in term of response amplitude.

Polar cap conjugated points map remarkable asymmetry in geomagnetic response to HSS event with a long lasting diurnal and short times periods, displaying most greater amplitudes in the $\mathrm{SH}$ than in the NH. A similar behavior is noted for scintillation activity.

At middle latitude conjugated pairs, we note a hemispheric asymmetry in the ionospheric disturbance dynamo generated by the Ddyn disturbance, with a longer duration in the SH than in the NH. On this longitude sector, a significant asymmetry associated to ionospheric VTEC (of about 11 tecu) is observed between the $\mathrm{NH}$ and $\mathrm{SH}$, during the studied period.

The results contained in this study highlight the importance of HSS flowing from a transient coronal hole (no recurrent), revealing how physical processes within the magnetosphereionosphere system respond to HSS event. The future works are to develop a statistical analysis of similar events during a solar cycle and to perform modeling of this ionospheric response.

\section{ACKNOWLEDGEMENT}

The authors thank the INTERMAGNET project who contribute to the collection of magnetic data.The authors also express their thanks to all institutes maintaining the magnetometer network at polar cap and maintaining the GPS stations. The authors gratefully acknowledge the International Service of Geomagnetic Indices (ISGI). 


\section{REFERENCE}

Benkevitch, L., W. Lyatsky, and L.L. Cogger (2000), Field aligned currents between Conjugate hemispheres, J. Geophys.Res., 105(A12), 27727-27737,doi: 10.1029/2000JA900095.

Benkevitch, L. and W. Lyatsky (2000), Detached vortices in equivalent ionospheric currents in the winter dayside ionosphere, J. Geophys.Res., 27 (9), 13751378,doi:10.1029/1999GL003711.

Blanc, M., and A. D. Richmond, (1980), The ionospheric disturbance dynamo, $J$. Geophys.Res., 85(A4), 1669-1686, doi: 10.1029/JA85iA04p01669.

Borovsky, J. E., and M. H. Denton, (2006), Differences between CME driven storms and CIR-driven storms, J. Geophys.Res., 111, A07S08,doi: 10.1029/2005JA011447.

Buresova, D., J. Lastovicka, P. Hejda ,and J. Bochnicek, (2014). Ionospheric disturbances under low solar activity conditions, Advances in Space Research, 54(2), 185-196, doi: 10.1016/j.asr.2014.04.007.

Cnossen, I., and A.D. Richmond (2012), How changes in the tilt angle of the geomagnetic dipole affect the coupled magnetosphere- ionosphere-thermosphere system, J. Geophys. Res., 117, A10317), doi: 10.1029/2012JAA0118056.

Cole, K. D. (1966), Magnetic Storms and Associated Phenomena, Space Science Reviews,5, 699-770,doi: 10.1007/BF00173103.

Coster, A.J., M. Colerici, J. Foster, B. Rideout, F. Rich, and B. Taylor (2006), Magnetic conjugacy of storm enhanced density, Abstract Coster 31370, National Radio Science Meeting, 4-7, University of Colorado, Boulder.

Cowley, S. W. H., J. P. Morelli, and M. Lockwood (1991), Dependence convective flows and particle precipitation in the high-latitude dayside ionosphere on the $\mathrm{x}$ and $\mathrm{y}$ components of the interplanetary magnetic field, J. Geophys. Res., 96, 5557-5564, doi: 10.1029/90JA02063. 
Davis T.N, and M. Sugiura (1966), Auroralelectrojet activity index $A E$ and its universal time variations, J. Geophys. Res., 71(3), 75-801, doi: 10.1029/JZ07i003p00785.

Denton, M. H., T. Ultich, and E. Turunen (2009), Modification of midlatitude ionospheric parameters in the F2 layer by persistent high-speed solar wind streams, Space Weather, 7, S04006, doi: 10.1029/2008SW000443.

Denton, M. H., and J. E. Borovsky (2008), Superposed epoch of high-speed stream effects at geosynchronous orbit: Hot plasma, cold plasma and the solar wind, J. Geophys. Res.,113, A07216, doi: 1029/2007JA012998.

Denton, M. H., and J. E. Borovsky (2009), The superdense plasma sheet in the magnetosphere during high-speed-stream-driven storms, J. of Atmos. Sol. Terr. Phys, 71, 10-11, 10451058, doi:10.1016/j.jastp.2008.04.023.

Fathy, I., C. Amory-Mazaudier, A. Fathy, A. M. Mahrous, K. Yumoto, and E. Ghamry (2014), Ionospheric disturbance dynamo associated to a coronal hole: Case study of 510April 2010, J. Geophys. Res.,Space Physics, 119, doi: 10.1002/2013JA019510.

Fejer,B.G.,M.F.Larsen,andD.T.Farley(1983), Equatorial disturbancedynamoelectricfields, Geophys. Res. Lett., 10,537-540, doi: 10.1029/GL010i007p00537.

Fejer, B.G., and L. Scherliess, (1997), Mid-and low-latitude prompt penetration ionospheric zonal plasma drifts,Geophys. Res.Lett., 25(16), 3071-3074,doi: 10.1029/98GL02325.

Fukushima, N., and Y. Kamide (1973), Partial ring current models for worldwide geomagnetic disturbances,Rev. Geophys. Space Phys., 11, 795-853, doi:

10.1029/RG011i004p00795. 
Gasda, S., and A. D. Richmond (1998), Longitudinal and interhemispheric variations of auroral ionospheric electrodynamics in a realistic geomagnetic field, J. Geophys. Res., 103(A3), 4011-4021, doi: 10.29/97JA03243.

Grandin, M., A. T. Aikio, A. Kozlovsky, T. Ulich, and T. Raita (2015), Effects of solar wind high-speed streams on the high-latitude ionosphere: Superposed-epoch study, J. Geophys. Res., 120, doi: 10.1002/2015JA021785.

Heelis, R. A., and J. J. Sojka (2011), Response of the topside ionosphere to high-speed solar wind streams, J. Geophys. Res., 116, A11314, doi: 1029/2011JA016739.

Hofmann-Wellenhof, B., H. Lichtenegger, and J. Collin (1992), Global positioning System: Theory and practice, ISBN 978-3-211-82839-7, Wien, New York, Springer-Verlag.

Huang, C. S., J. C. Foster, and P. J. Erikson (2002), Effect of solar wind on the midlatitude ionosphere, J. Geophys. Res., 107(A8), doi: 10.1029/2001JA009025.

Huang, C. S., J. C. Foster, L. P. Goncharenko, G. D. Reeves, J. L. Chau, K. Yumoto, and K. Kitamura (2004), Variations of low-latitude geomagnetic fields and Dst index caused by magnetosphericsubstorms, J. Geophys. Res., 109(A5), doi:10.1029/2003JA010334.

Huang, C.S. (2012), Equatorial ionospheric electrodynamics associated with high-speedsolar wind streams during January-April 2007, J. Geophys. Res., 117, A10311, doi: 10.1029/2012JA017930.

Kavanagh, A. and H. Denton (2007), High speed solar wind stream and geospace interactions, Astron.\&Geophys., 48, 6.24-6.26,doi: 10.1111/j.1468-4004.

Kikuchi, T., and K. K. Hashimoto (2016), Transmission of the electric fields to the low latitude ionosphere in the magnetosphere-ionosphere current circuit, Geosci. Lett, 3:4, doi: 10.1186/s40562-016-0035-6. 
Kim, H., X. Cai, C. R. Clauer, B. S. R Kunduri, J. Matzka, C. Stolle, and D. R. Weimer (2013), Geomagnetic response to solar wind dynamic pressure impulse events at highlatitude conjugate points, J. Geophys Res., 118(10), 6055-6071,doi:10.1002/jgra.50555.

Kobéa, A. T., C. Amory-Mazaudier, J.M. Do, H. Lürh, J. Vassal, E. Houngninou, E. Blanc, and J.J. Curto (1998), Equatorial electrojet as part of a global current system: a case-study from the IEEY,Ann.Geophys., 16, 6, 698-710, doi:10.1007/s00585-998-0698-1.

Kobéa, A. T., A. D. Richmond, B. A. Emery, C. Peymirat, H. Luhr, T. Moretto, M. Hairston, and C. Amory-Mazaudier (2000), Electrodynamic Coupling of High and Low latitudes Observations on May 27, 1993, J. Geophys. Res., 105(A10), 22979-22989, doi:10.1029/2000JA000058.

Laudal, K., M. N. Østgaard, K. Snekvik, and H.U. Frey(2010), Interhemispheric observations of emerging polar cap asymmetries, J. Geophys. Res., 115, A07, A07230, doi: 10.29/2009JA015160.

Le Huy, M., and C. Amory-Mazaudier (2005), Magnetic signature of the ionospheric disturbance dynamo at equatorial latitudes: "Ddyn", J. Geophys. Res., 110, A10301 doi: 10.1029/2004JA010578.

Mayaud, P. N. (1980), Derivation, Meaning and Use of Geomagnetic Indices, Geophys.Monogr.Ser., v22, 154 pp., AGU, Washington, D. C.

Mayaud, P.N. (1970), Sur quelques propriétés de l'activité magnétique déduites de l'analyse d'une série de neuf années des indices Kn, Ks et Km ; I- Comparaison des niveaux d'activité dans chaque hémisphère, Ann. Géophys., 26, 1, 109-126.

Mazaudier , C., M. Blanc, E. Nielsen, Z. Min-Yun, (1984) Latitudinal profile of the magnetospheric convection electric field at ionospheric altitudes from a chain of magnetic and radar data, J. Geophys. Res., 89, (A1), 375-381,1984. 
Mene, N. M., A. T. Kobéa, O. K. Obrou, K. Z. Zaka, K. Boka, C. Amory-Mazaudier, and P. Assamoi (2011), Statistical study of the DP2 enhancement at the dayside dip-equator compared to low latitudes, Ann. Geophys., 29, 2225-2233, doi:10.5194/angeo-29-22252011.

Menvielle, M., and A. Marchaudon (2008), Geomagnetic indices, in Solar-Terrestrial Physics and Space Weather in Space Weather, edited by J. Lilensten, pp. 277-288, Springer, Netherlands, doi: 10.1007/1-4020-5446-7_24.

Newell, P.T., T. Sotirelis, K. Liou, C. I. Meng, and F. J. Rich (2007), A nearly universal solar wind-magnetosphere coupling function inferred from 10 magnetospheric state variables,$J$. Geophys. Res., 112, A01206, doi: 10.29/2006JA012015.

Nishida, A. (1968), Geomagnetic DP2 fluctuations and associatedmagnetospheric phenomena, J. Geophys.Res., 73, 1795-1803, doi: 10.1029/JA073i005p01795.

Østgaard, N. and K.M. Laundal, (2012), Auroral asymmetries in the conjugate hemispheres and interhemispheric currents. Auroral Phenomenology and Magnetospheric Processes: Earth and Other Planets, pp99-112, (eds A. Keiling, E. Donovan, F. Bagenal and T. Karlsson), American Geophysical Union, Washington, D. C., doi: 10.1029/2011GM001190.

Østgaard, N., N. A. Tsyganeneko, S. B. Mende, and J. B. Sigwarth (2005), Observations and model predictions of substormauroral asymmetries in the conjugate hemisphere, Geophys. Res.Lett.32 (5), doi: 10.29/2004GL022166.

Pedatella, M., and M. Forbes (2011), Electrodynamic response of the ionosphere to highspeed solar wind streams, J. Geophys. Res., 116, A12310, doi: 1029/2011JA017050.

Peymirat, C., A. D. Richmond, and A. T.Kobea (2000), Electrodynamic coupling of high and low latitudes: simulations of shielding and overshielding effects, J. Geophys. Res., 105, 22991-23003,doi:10.1029/2000JA000057. 
Pi, X., A. J. Mannucci, U. J. Linqwister, and C. M. Ho (1997), Monitoring of global ionospheric irregularities using Worldwide GPS Network, Geophys.Res.Lett., 24 (18), 2283-2286, doi:10.1029/97GL02273.

Prikryl, P., L. Spogli, P. T. Jayachandran, J. Kinrade, C. N. Mitchell, B. Ning, G. Li, P. J. Cilliers, M. Terkildsen, D. W. Danskin, E. Spanswick, E. Donovan, A. T. Weatherwax, W. A. Bristow, L. Alfonsi, G. De Franceschi, V. Romano, C. M. Ngwira, and B. D. L. Opperman (2011), Interhemispheric comparison of GPS phase scintillation at high latitudes during the magnetic-cloud-induced geomagnetic storm of 5-7 April 2010, Ann.Geophys., 29, 2287-2304, doi:10.5194/angeo-29-2287-2011.

Prikryl, P., P. T. Jayachandran, S. C. Mushini, and I. G. Richardson, (2014), High-latitude GPS phase scintillation and cycle slips during high-speed solar wind streams and interplanetary coronal mass ejections: a superposed epoch analysis, Earth Planets and Space, 66(1),doi : 10.1186/1880-5981-66-62.

Prikryl, P., R. Ghoddouci-Fard, E. G. Thomas, J. M Ruohoniemi, S. G. Sheperd, P. T. Javachandran, D. W. Danskin, E. Spaniswck, Y. Zhang, Y. Jiao, and Y. T. Morton (2015),GPS scintillation at high latitudes during geomagnetic storms of 7-17 March 2012 Part 1: The north American sector, Ann. Geophys., 33, 637-656, doi: 10.5194/angeo-33637-2015.

Richmond, A.D. and R.G. Roble (1987), Electrodynamic effects of thermospheric winds from the NCAR thermospheric general circulation model, J. Geophys. Res., 92(A11): 1236512376, doi:10.1029/JA092iA11p12365.

Richmond, A.D., C. Peymirat, and R.G. Roble (2003), Long-Lasting disturbances in the equatorial ionosphere electric field simulated with a coupled magnetosphere-ionospherethermosphere model, J. Geophys. Res., 108 (A3), 1118, doi:10.1029/2002JA009758.

Sabaka, T. J., N. Olsen, and M. E. Purucker (2004), Extending comprehensive models of the Earth magnetic field with Oersted and Champ data, Geophys. J. Int., 159, 521-547, doi:10.1111/j.1365-246X.2004.02421.x. 
Schaer, S. (1999) Mapping and prediction the Earth's ionosphere using the Global Positioning System, Thesis, 228p,University of Bern.

Spiro, R. W., R. A. Wolf, and B. G. Fejer (1988), Penetration of high latitude electric field effects to low latitudes during the SUNDIAL 1984, Ann. Geophys., 6, 39-49.

Stauning P., (2012), The Polar Cap PC Indices: Relations to Solar Wind and Global Disturbances, Exploringthe Solar Wind, Dr. Marian Lazar (Ed.), ISBN: 978-953-51-03394, InTech, Available from:http://www.intechopen.com/books/exploring-the-solar-wind/thepolar-cap-pc-indices-relations-to-solar-windand-global-disturbances.

Storini,M., M.Y. Hofer, and J. Sýkora (2006),Towards the understanding of coronal hole occurrence during the Schwabe cycle, Adv. in Space Res., 38, 912-920, doi: 10.1016/j.asr.2006.03.024.

Tsurutani, B. T., R. L. McPherron, W. D. Gonzalez, G. Lu, J. H. A. Sobral, and N. Gopalswamy (2006), Introduction to special section on corotating solar wind streams and recurrent geomagnetic activity: A review, J. Geophys. Res., 111, A07S00, doi: 10.1029/2006JA011273747.

Tsurutani, B. T., W. D. Gonzalez, F. Guarnieri, Y. Kamide, X. Zhou, and J. K. Arballo (2004), Are high-intensity long-duration continuous AE Activity (HLDCAA) event substorm expansion events,J. Atmos. Sol.-Terr. Phys., 66,167-176, doi: 10.1016/j.jastp.2003.08.015.

Turner, N.E., W.D. Cramer, S.K.Earles, and B.A. Emery (2009), Geoefficiencyand energy partitioning in CIR-driven and CME-driven storms, J. Atmos. Sol.-Terr. Phys., 71, 10-11, 1023-1031, doi:10.1016/j.jastp.2009.02.005.

Vasyliunas, V. M. (1970), Mathematical models of the magnetospheric convection and its coupling to the ionosphere, in Particles and Fields inthe Magnetosphere, edited by McCormac, 60-71, Springer, New-York, doi:10.1007/978-94-010-3284-1-6. 
Verkhoglyadova, O. P., B. T. Tsurutani, A.J. Mannucci, M. G. Mlynczak, L. A. Hunt, and T. Runge, (2013),Variability of ionospheric TEC during solar and geomagnetic minima (2008 and 2009): external high speed stream drivers. Ann. Geophys, 31(2), p. 263-276, doi: 10.5194/angeo-31-263-2013.

Wagner, C. U., D. Moehlmann, K. Schaefer, V. M. Mishin, and M. I. Matveev (1980), Large scale electric field and currents and related geomagnetic variations in the quiet plasmasphere, Space Science Reviews, 26, 391-446, doi: 10.1007/BF00217388.

Weimer, D. R., (1995), Models of high-latitude electric potential derived with a least-error fit of spherical harmonic coefficients, J. Geophys. Res., A10, 100, 19595-19607, doi: 10.1029/95JA01755.

Zaka, K. Z., A. T. Kobea, P. Assamoi, O. K. Obrou, V. Doumbia, K. Boka, B. J. P. Adohi, and M. N. Mene (2009), Latitudinal profile of the ionospheric disturbance dynamo magnetic signature: comparison with the DP2 magnetic disturbance, Ann. Geophys., 27, 3523-3536, doi:10.5194/angeo-27-3523-2009.

Zaourar, N., M. Hamoudi, M. Mandea, G. Balasis, and M. Holschneider (2013), Waveletbased multiscale analysis of geomagnetic disturbance,Earth Planets and Space, 65, 15251540, doi: 10.5047/eps.2013.05.001. 


\section{TABLe CAPTiON}

Table 1. Geographic and geomagnetic coordinates of the magnetic observatories and the GNSS receivers, the * indicate the GNSS conjugate positions.

Table 2.Daily values of the Am index from 20 to 31 August 2010. The quiet days are ones for which the Am $<20 \mathrm{nT}$. The quietest days selected in this study are in bold.

Table 3a.Time occurrence of minima and amplitude of minima of the $\mathrm{D}_{\text {ionoionospheric disturbance }}$ dynamo for low and equatorial latitude observatories.

Table 3b.Time occurrence of minima and amplitude of minima of the $\mathrm{D}_{\text {iono }}$ ionospheric disturbance dynamo forsub-auroral, auroral and polar cap latitude observatories.

Table 4.Frequency and period values of $\mathrm{D}_{\text {iono }}$ equivalent current. 


\section{FIGURE CAPTIONS}

Figure1. World map of INTERMAGNET observatories and GPS stations used in this study. Geomagnetic latitudes conjugated pairs are indicated by various symbols. Red circles: polar cap latitudes; blue circles and square: auroral latitudes; magenta star: sub auroral latitudes; red asterisk: middle latitudes; black squares: low and equatorial latitudes

Figure 2.Variations of solar wind parameters and geomagnetic indices, from 20 to 31 August 2010. From top to bottom: component Vx of the solar wind speed, the Bz component of the interplanetary magnetic field, the Dst index and the AU and AL indices.

Figure 3. Superposition of $\left\langle S_{R}(H)\right\rangle$ the mean regular variation of the Earth's magnetic field as blue curve and the ionospheric electric disturbance $D_{\text {iono }}$ as red curve from 20 to 31 August 2010. (a): at equatorial and low latitude. (b): at middle latitude conjugate pair in the NH (left side) and in SH (right side).

Figure 4.Superposition of $\left\langle\mathrm{S}_{\mathrm{R}}(\mathrm{H})\right\rangle$ the mean regular variation of the Earth's magnetic field as blue curve and the ionospheric electric disturbance $D_{\text {ionoas }}$ red curve from 20 to 31 August 2010, of the various latitudes conjugated pairs in the NH (left side) and in the SH (right side). (a): sub-auroral, (b): auroral, (c): polar cap.

Figure 5.Fourier power spectra of $D_{\text {iono }}$ electric ionospheric variations. Top: equatorial (HUA and AAE) latitudes. Middle: middle (KIV) and sub-auroral (SHU) latitudes. Bottom: Auroral (BRW) and polar cap (RES) latitudes. The straight lines are the linear least squares fit. The slope of the regression line, indicated on each plot, reveals the global exponent $\beta$.

Figure 6.Scalograms revealing the amplitude wavelet coefficients of $D_{\text {iono. (a): equatorial }}$ (HUA) and low (AAE,MBO) latitudes. (b):middle latitudes conjugated pairs of observatories. observatories from the $\mathrm{NH}$ are in the left side and its conjugated from the $\mathrm{SH}$ are in the right side. The color scale reflects the increasing amplitude from blue to purple.

Figure 7.Scalograms revealing the amplitude wavelet coefficients of $D_{\text {iono }}$ for latitudes conjugated pairs of observatories (a): sub-auroral, (b):auroral, (c): polar cap. Observatories 
from the $\mathrm{NH}$ are in the left side and its conjugated from the $\mathrm{SH}$ are in the right side. The color scale reflects the increasing amplitude from blue to purple.

Figure 8.Location of GPS stations at conjugated points and VTEC variations for HSS event on 24 August 2010. The color square is blue for VTEC depletion, red for minor enhanced VTEC and black for high enhanced VTEC. The Black line is for magnetic equator

Figure 9.VTEC variations at conjugated stations located at NH (left side) and SH (right side). (a) polar, (b) auroral, (c) sub auroral and (d) middle latitudes.

Figure 10.ROTI index at conjugated stations located at NH (blue) and SH (red). (a) polar, (b) auroral and (c) sub auroral latitudes. 
Table. 1 Geographic and geomagnetic coordinates of magnetic observatories and GNSS stations

\begin{tabular}{|c|c|c|c|c|c|c|}
\hline \multirow[t]{2}{*}{ Regions } & \multirow[t]{2}{*}{ Code } & \multirow[t]{2}{*}{ Name } & \multicolumn{2}{|c|}{ Geographic } & \multicolumn{2}{|c|}{ Geomagnetic } \\
\hline & & & Latitude & Longitude & Latitude & Longitude \\
\hline \multirow{4}{*}{ Polar cap } & & & Magnetometers & & & \\
\hline & RES & Resolute Bay & 74.69 & 265.10 & 82.73 & 305.99 \\
\hline & SBA & Scott Base & -77.85 & 166.78 & -78.94 & 288.85 \\
\hline & BRW & Barrow & 71.32 & 203.38 & 69.68 & 247.45 \\
\hline \multirow{3}{*}{ Auroral } & MCQ & Macquarie & -54.50 & 158.95 & -59.70 & 244.22 \\
\hline & $\mathrm{ABK}$ & Abisko & 68.35 & 18.82 & 65.81 & 113.37 \\
\hline & MAW & Mawson & -67.60 & 62.88 & -73.08 & 111.61 \\
\hline \multirow{2}{*}{$\begin{array}{c}\text { Sub } \\
\text { auroral }\end{array}$} & SHU & Shumagin & 55.35 & 199.54 & 54.24 & 102.30 \\
\hline & EYR & Eyrewell & -43.42 & 172.35 & -46.78 & 106.07 \\
\hline \multirow{2}{*}{ Middle } & KIV & Ukraine & 50.72 & 30.30 & 47.42 & 113.47 \\
\hline & $\mathrm{CZT}$ & Port Alfred & -46.43 & 51.87 & -51.11 & 114.12 \\
\hline \multirow[b]{2}{*}{ Low } & MBO & Mbour & 14.38 & 343.03 & 19.96 & 303.21 \\
\hline & AAE & AddisAbaba & 09.03 & 38.77 & 5.3 & 110.41 \\
\hline equatorial & HUA & Huancayo & -12.5 & 284.67 & -2.45 & 356.95 \\
\hline \multicolumn{7}{|c|}{ GNSS receivers } \\
\hline \multirow{3}{*}{ Polar cap } & RESO & Resolute Is.* & 74.69 & 265.10 & 82.73 & 305.96 \\
\hline & MCM4 & Ross Is.* & -77.83 & 166.62 & -79.06 & 289.36 \\
\hline & HOLM & Holman & 70.74 & 242.26 & 75.77 & 285.42 \\
\hline \multirow{8}{*}{ Auroral } & BRW1 & Brewster * & 71.28 & 203.21 & 69.62 & 247.36 \\
\hline & MAC1 & Macquarie Is.* & -54.50 & 158.93 & -59.70 & 244.20 \\
\hline & TRO1 & Tromsoe* & 69.66 & 18.94 & 67.15 & 115.85 \\
\hline & SYOG & East Ongle Is* & -69.00 & 39.58 & -70.36 & 84.89 \\
\hline & JOEN & Joensuu* & 62.39 & 30.09 & 58.70 & 118.83 \\
\hline & KERG & Port aux Français* & -49.35 & 70.25 & -56.62 & 133.63 \\
\hline & YEL2 & Yellowknife & 62.49 & 245.52 & 68.71 & 300.62 \\
\hline & QAQ1 & Qaqortoq & 60.72 & 313.95 & 69.09 & 37.39 \\
\hline \multirow{4}{*}{$\begin{array}{c}\text { Sub } \\
\text { Auroral }\end{array}$} & AB07 & Sand Point* & 53.34 & 199.52 & 52.32 & 258.60 \\
\hline & MQZG & Christchurch* & -43.70 & 172.65 & -47.03 & 254.23 \\
\hline & OHI2 & O’Higgins & -63.32 & 302.10 & 53.42 & 10.79 \\
\hline & HOB2 & Hobart & -42.81 & 147.44 & 49.92 & 226.81 \\
\hline \multirow{5}{*}{ Middle } & LAMP & Lampedusa* & 35.50 & 12.60 & 35.60 & 91.96 \\
\hline & SUTM & Sutherland* & -32.38 & 20.81 & -37.02 & 115.68 \\
\hline & OSJE & Osijek & 45.56 & 18.68 & 44.35 & 100.82 \\
\hline & USUD & Usuda & 36.13 & 133.36 & 27.22 & 207.59 \\
\hline & SANT & Santiago & -33.15 & 289.33 & 23.00 & 1.41 \\
\hline Low & DARM & Darwin & -12.42 & 21.49 & 21.49 & 204.33 \\
\hline
\end{tabular}


Table 2. Daily values of the Am index from 20 to 31 August 2010. The quiet days are ones for which the $\mathrm{Am}<20 \mathrm{nT}$. The quietest days selected in this study are in bold.

\begin{tabular}{lllllllllllll} 
Day & 20 & 21 & 22 & 23 & 24 & 25 & 26 & 27 & 28 & 29 & 30 & 31 \\
\hline Am & $\mathbf{3}$ & $\mathbf{3}$ & $\mathbf{1}$ & 8 & 36 & 32 & 18 & 25 & 15 & $\mathbf{2}$ & $\mathbf{1}$ & $\mathbf{3}$ \\
\hline
\end{tabular}


Table 3a.Time occurrence of minima and amplitude of minima the $\mathrm{D}_{\text {iono }}$ Ionospheric disturbance Dynamo for low and equatorial latitude observatories.

\begin{tabular}{|c|c|c|c|c|}
\hline Station & Day & $\begin{array}{l}\text { Amplitude of } \\
\text { minima (nT) }\end{array}$ & $\begin{array}{c}\text { Time of } \\
\text { occurrence (UT) }\end{array}$ & $\begin{array}{c}\text { Time of } \\
\text { occurrence (LT) }\end{array}$ \\
\hline$A A E$ & & -36.99 & $7: 26$ & $10: 26$ \\
\hline$M B O$ & 24 August 2010 & -22.63 & $15: 23$ & $14: 23$ \\
\hline HUA & & -74.19 & $02: 40$ & $21: 40$ \\
\hline$A A E$ & & -40.50 & $6: 13$ & $9: 13$ \\
\hline$M B O$ & 25 August 2010 & -23.50 & $12: 42$ & $11: 42$ \\
\hline HUA & & -46.05 & $22: 00$ & $17: 00$ \\
\hline$A A E$ & & -31.54 & $11: 58$ & 14.58 \\
\hline$M B O$ & 26 August 2010 & -24.58 & $14: 34$ & $13: 34$ \\
\hline HUA & & -31.10 & $16: 41$ & $11: 41$ \\
\hline$A A E$ & & -18.80 & $10: 50$ & $13: 50$ \\
\hline$M B O$ & 27 August 2010 & -23.81 & $16: 50$ & $15: 50$ \\
\hline$H U A$ & & -82.61 & 15.35 & $10: 35$ \\
\hline$A A E$ & & -31.09 & $12: 54$ & $15: 54$ \\
\hline$M B O$ & 28 August 2010 & -13.52 & $10: 26$ & $9: 26$ \\
\hline HUA & & -54.38 & $16: 03$ & $11: 03$ \\
\hline
\end{tabular}


Table 3b.Time occurrence of minima and amplitude of minima of the $\mathrm{D}_{\text {iono }}$ Ionospheric disturbance Dynamo for sub-auroral, auroral and polar cap latitude observatories.

Observatory Day Amplitude of minima Time of occurrence Time of occurrence (nT) (UT) (LT)

\begin{tabular}{|c|c|c|c|c|}
\hline \multicolumn{5}{|c|}{ Sub- Auroral } \\
\hline SHU & & -69.67 & $08: 53$ & $21: 53$ \\
\hline EYR & 24 August 2010 & -35.01 & 07:19 & $19: 19$ \\
\hline SHU & & -98.46 & 05:00 & $19: 41$ \\
\hline EYR & 25 August 2010 & -45.52 & 04:41 & $16: 41$ \\
\hline SHU & & -52.73 & $07: 31$ & $20: 31$ \\
\hline EYR & 26 August 2010 & -26.63 & 04:00 & $16: 00$ \\
\hline SHU & 27 August 2010 & -66.57 & $07: 31$ & $20: 31$ \\
\hline EYR & & -43.37 & $07: 32$ & $19: 32$ \\
\hline SHU & 28 August 2010 & -37.70 & $07: 58$ & $20: 58$ \\
\hline EYR & & -22.27 & $06: 37$ & $18: 37$ \\
\hline \multicolumn{5}{|c|}{ Auroral } \\
\hline BRW & & -680.17 & 11:40 & 01:40 \\
\hline $\mathrm{ABK}$ & 24 August 2010 & $-186.02 ;-520.65$ & $02: 13 ; 22: 05$ & 03:13; 23:05 \\
\hline MCQ & & -584.45 & $12: 36$ & $22: 36$ \\
\hline MAW & & -511.34 & $22: 36$ & $00: 36$ \\
\hline BRW & & -766 & 10:39 & 00:39 \\
\hline $\mathrm{ABK}$ & 25 August 2010 & $-389.40 ;-483.36$ & $02: 66 ; 23: 39$ & $03: 66 ; 24: 39$ \\
\hline MCQ & & -435.77 & 10:14 & $20: 14$ \\
\hline MAW & & $-440.40 ;-184.33$ & $04: 50 ; 21: 46$ & 08:50; 01:46 \\
\hline BRW & & -546.33 & 09:00 & 23:00 \\
\hline $\mathrm{ABK}$ & 26 August 2010 & -400.28 & $01: 15$ & $02: 15$ \\
\hline MCQ & & -247.65 & $10: 38$ & $20: 38$ \\
\hline MAW & & -190.89 & $21: 45$ & $01: 47$ \\
\hline BRW & & -724.09 & $10: 31$ & 00:31 \\
\hline $\mathrm{ABK}$ & 27 August 2010 & -467.71 & $22: 56$ & $23: 56$ \\
\hline MCQ & & -185.14 & $14: 21$ & $00: 21$ \\
\hline MAW & & -643.18 & $22: 54$ & $02: 54$ \\
\hline BRW & & -585.50 & $12: 34$ & $02: 31$ \\
\hline $\mathrm{ABK}$ & 28 August 2010 & -272.57 & $00: 38$ & $01: 38$ \\
\hline MCQ & & -120.58 & $12: 28$ & $22: 28$ \\
\hline MAW & & -162.54 & $21: 49$ & 01:49 \\
\hline \multicolumn{5}{|c|}{ Polar cap: minima and maxima of Diono amplitude } \\
\hline RES & 24 August 2010 & -223.30 & $18: 49$ & $12: 49$ \\
\hline SBA & & 91.48 & $06: 51$ & $17: 51$ \\
\hline RES & 25 August 2010 & $-165: 04$ & $18: 56$ & $12: 56$ \\
\hline SBA & & 205.81 & $11: 53$ & $22: 53$ \\
\hline RES & 26 August 2010 & -138.18 & $17: 76$ & $11: 56$ \\
\hline SBA & & 105 & $10: 31$ & $22: 31$ \\
\hline RES & 27 August 2010 & -104.66 & $18: 56$ & $12: 56$ \\
\hline SBA & & 195.63 & $11: 16$ & $22: 16$ \\
\hline RES & 28 August 2010 & -108.85 & $19: 05$ & $13: 05$ \\
\hline SBA & & 162.53 & $07: 15$ & $18: 15$ \\
\hline
\end{tabular}


Table 4.Frequency and period values of $\mathrm{D}_{\text {iono. }}$.

\begin{tabular}{ccccc}
$\log _{10}$ (Frequency(1/Day) & 0 & 1 & 1.5 & 2 \\
\hline Period & $24 \mathrm{~h}$ & $2.4 \mathrm{~h}$ & $45 \mathrm{~min}$ & $14 \mathrm{~min}$ \\
\hline
\end{tabular}




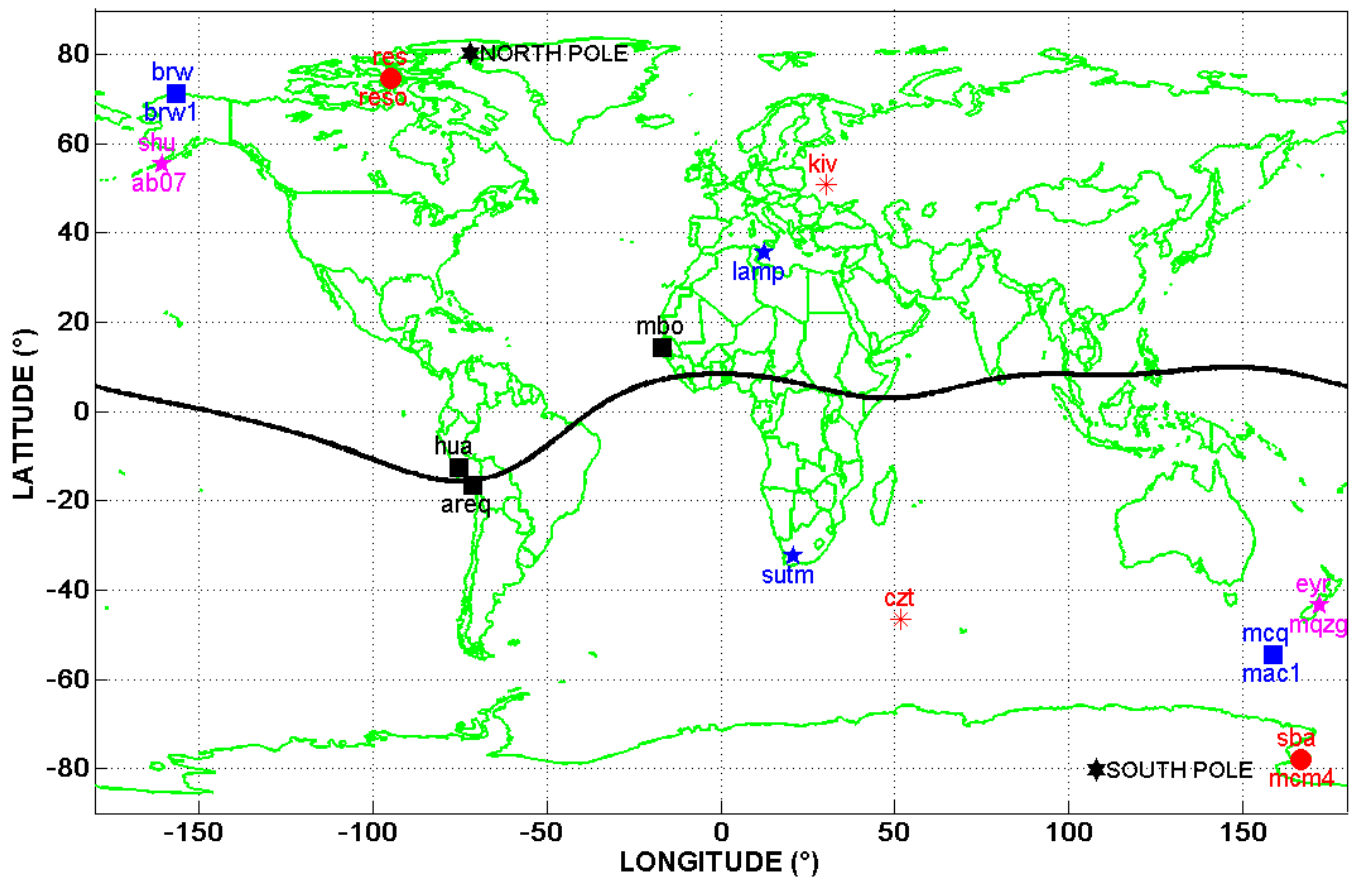

Figure 1 

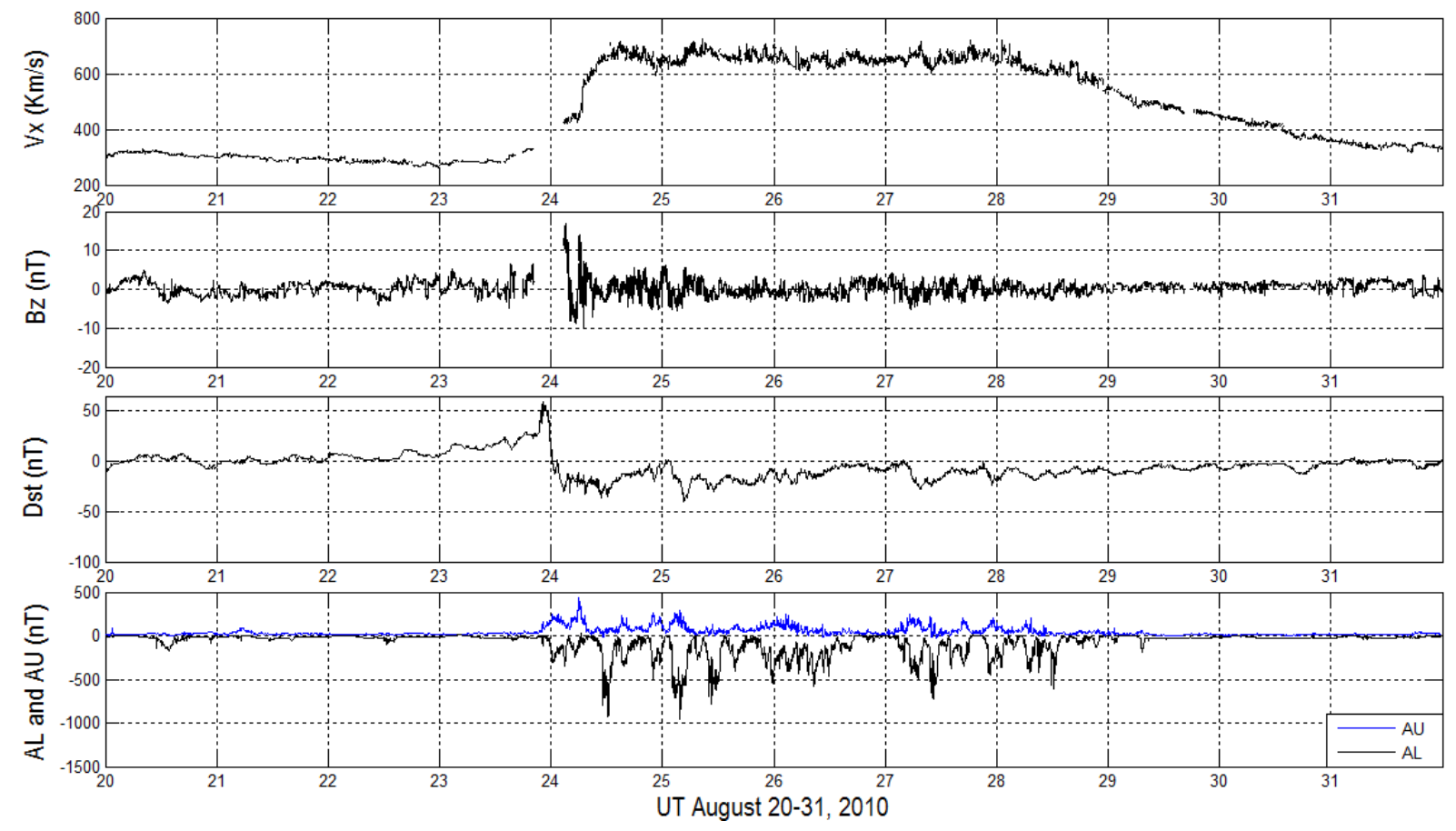

Figure 2 

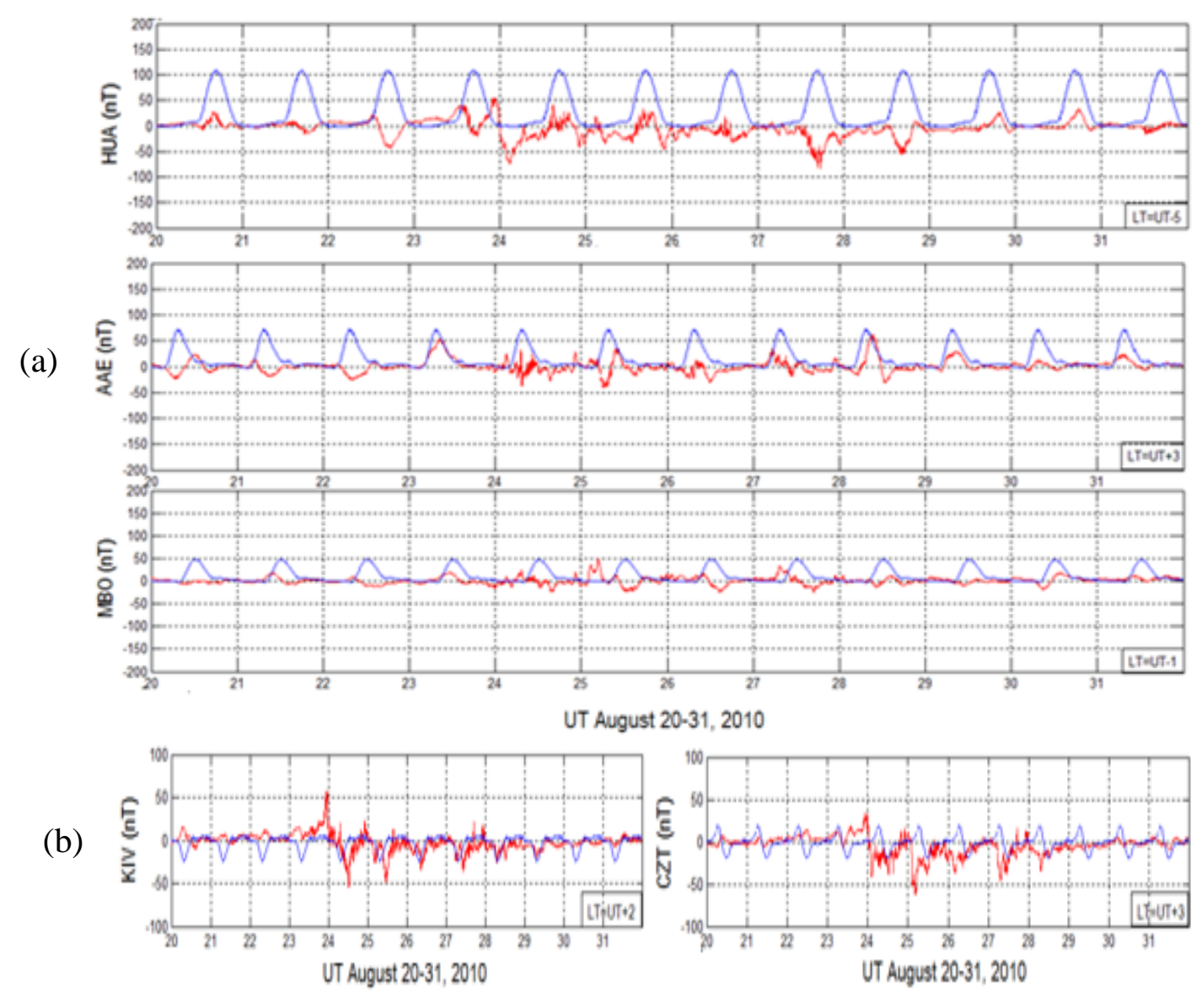

Figure 3 

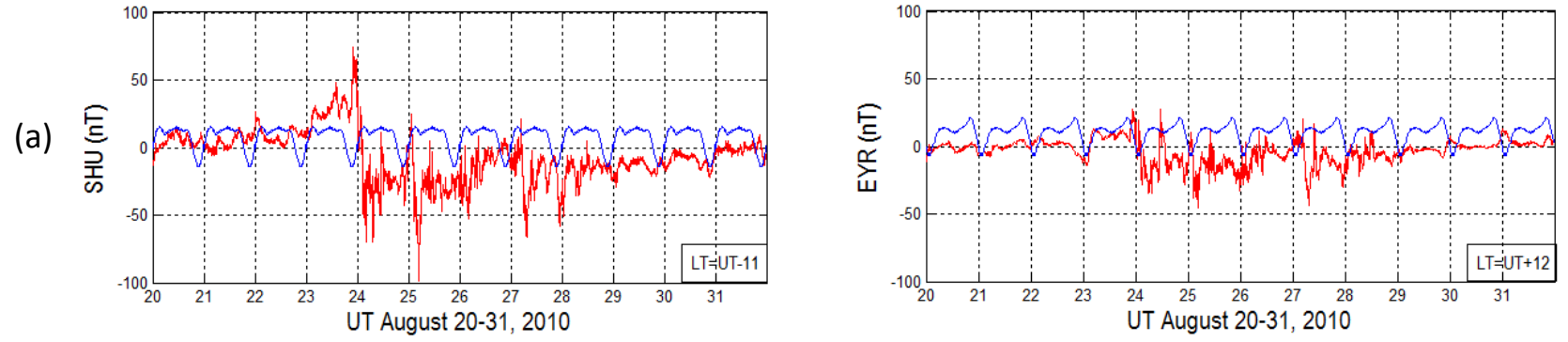

(b)
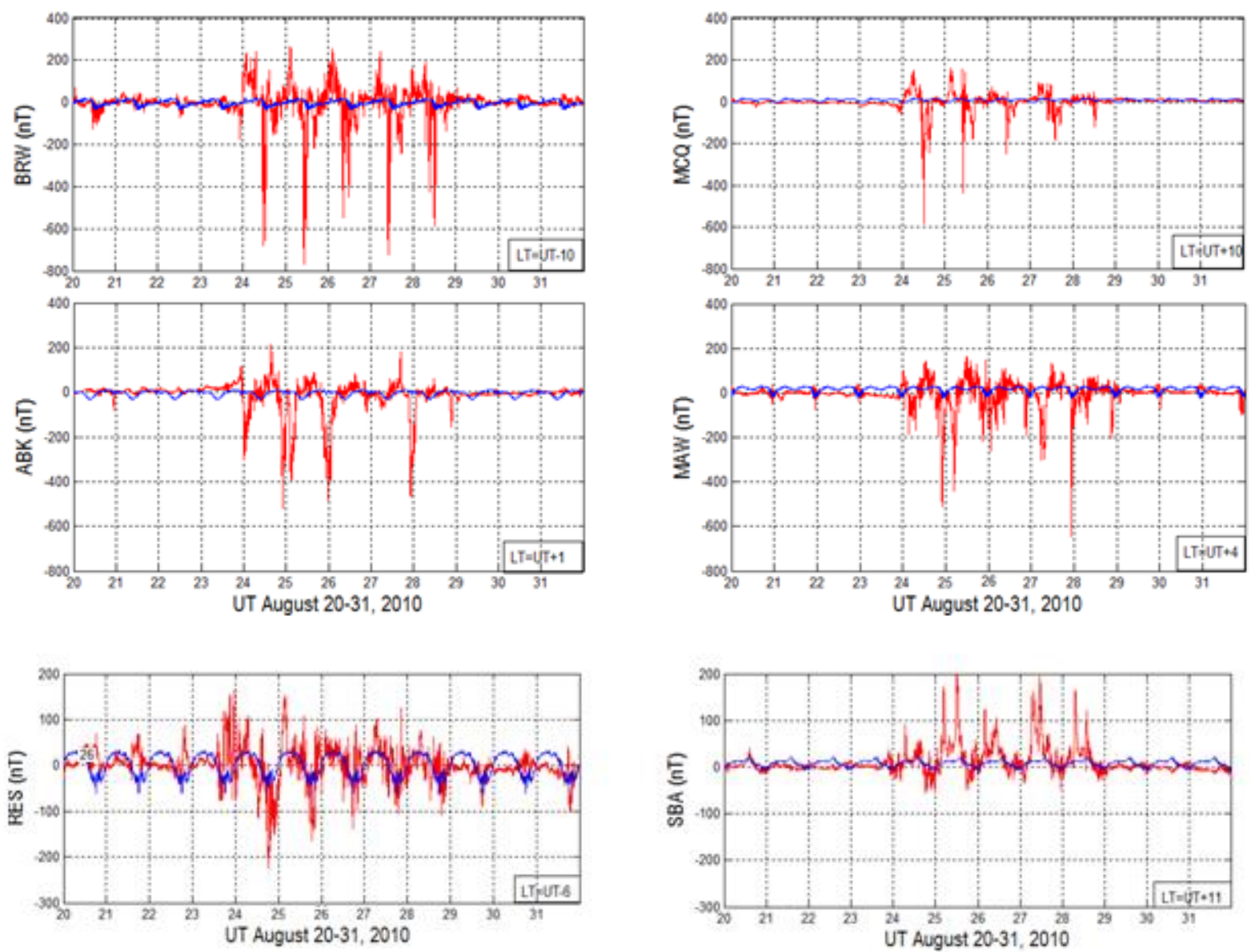

Figure 4 


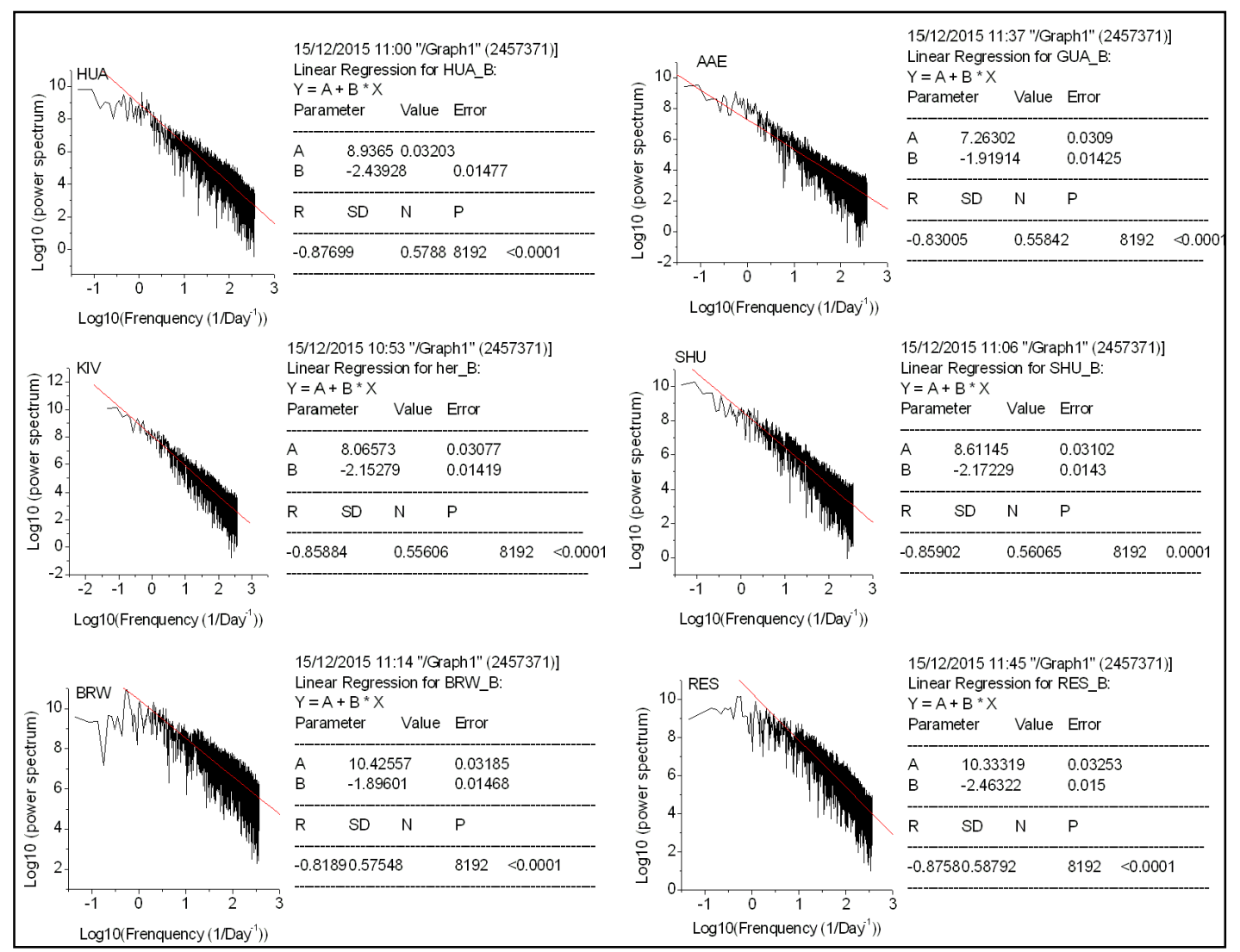

Figure 5 

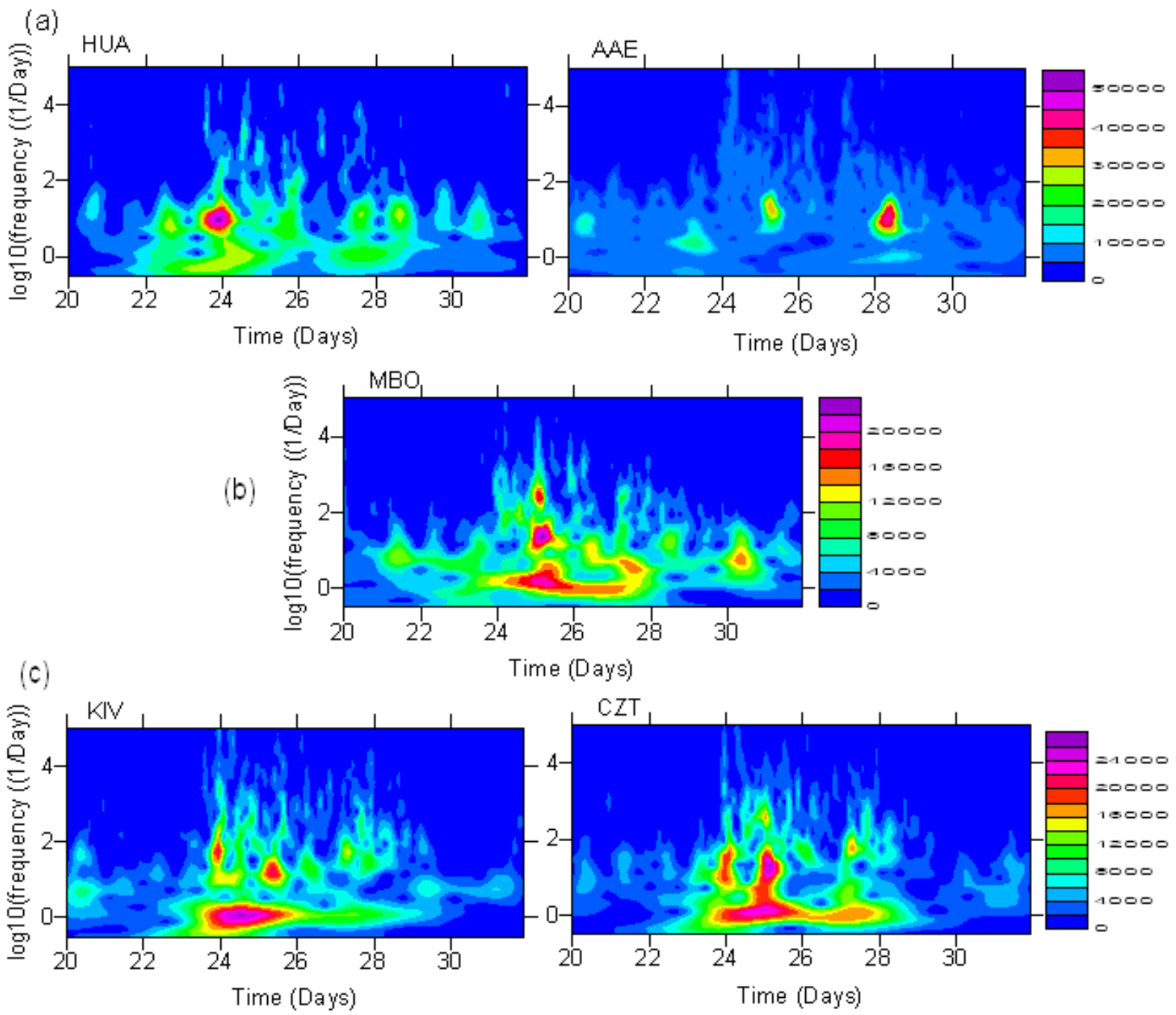

Figure 6 
(a)

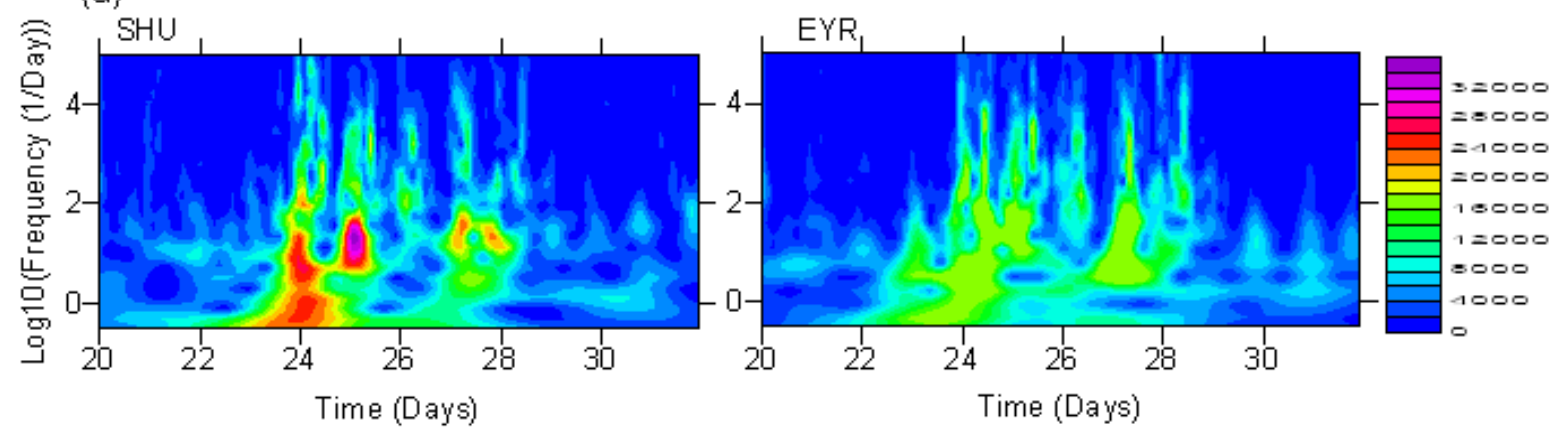

(b)
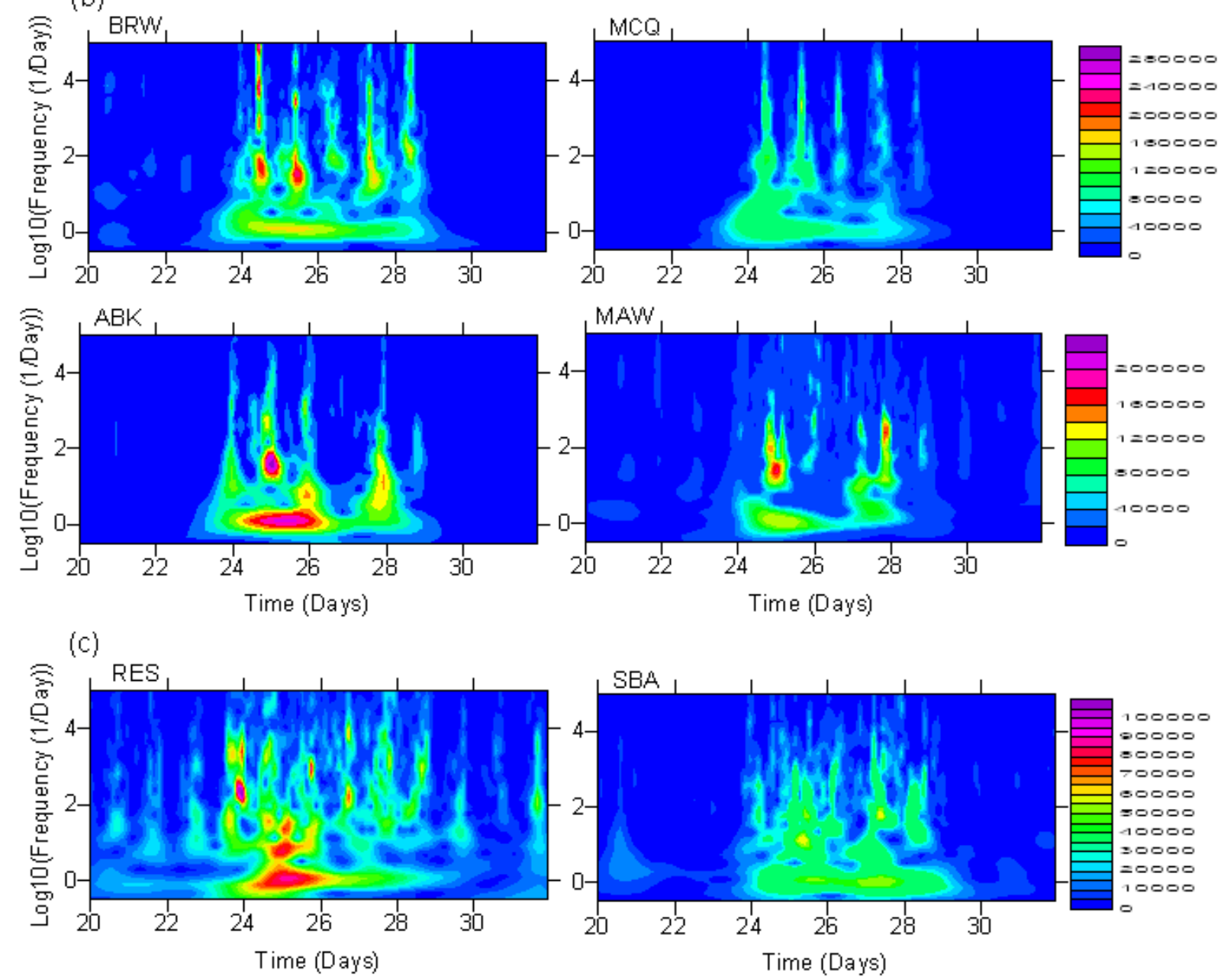

Figure 7 


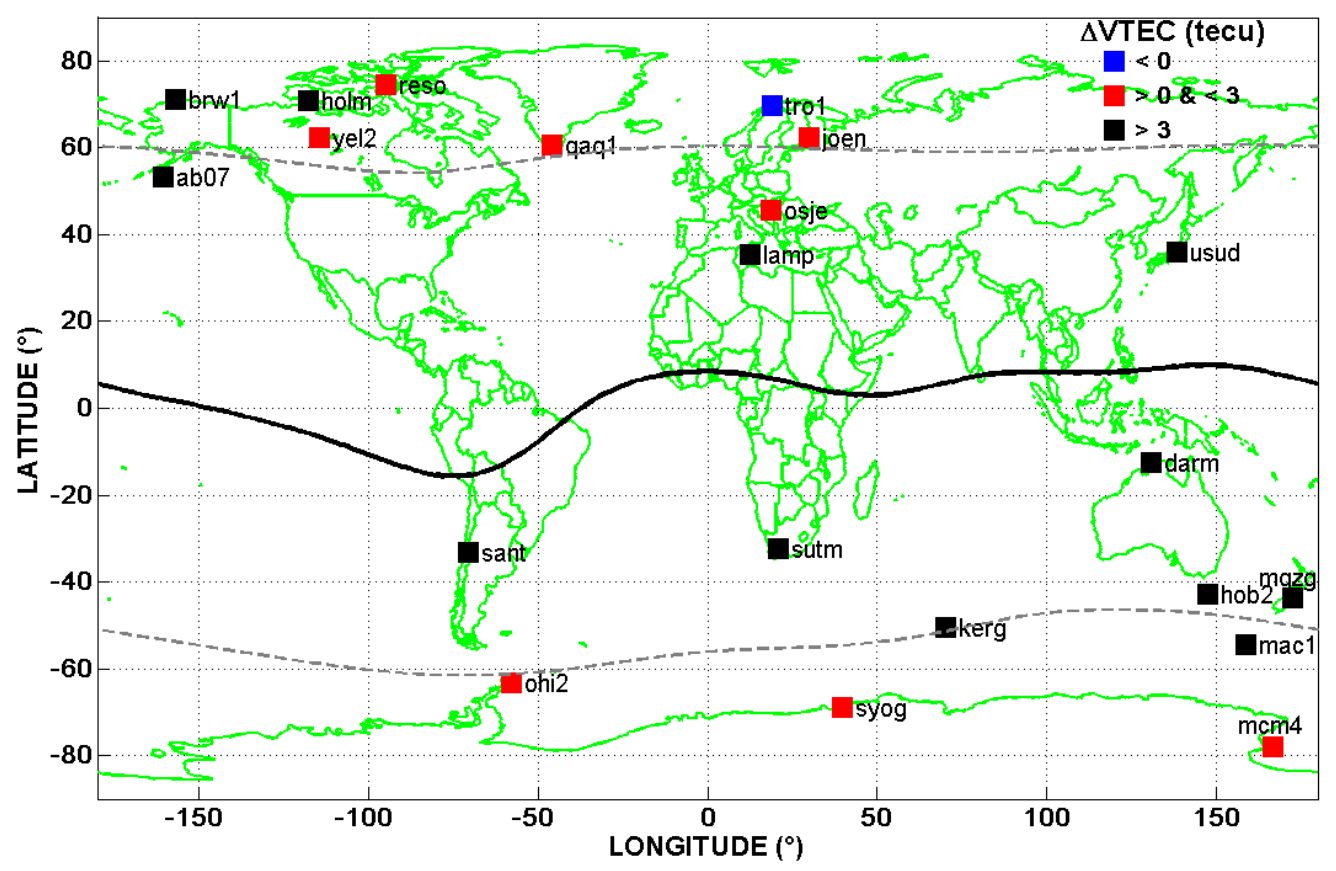

Figure 8 

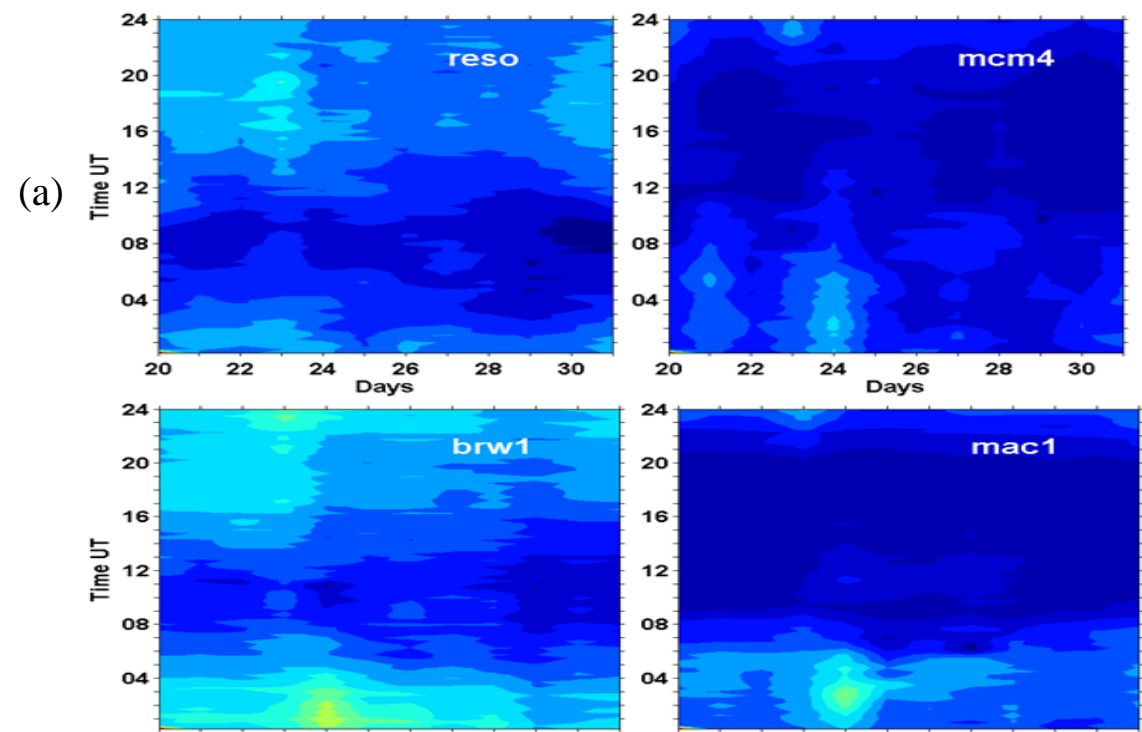

(b)
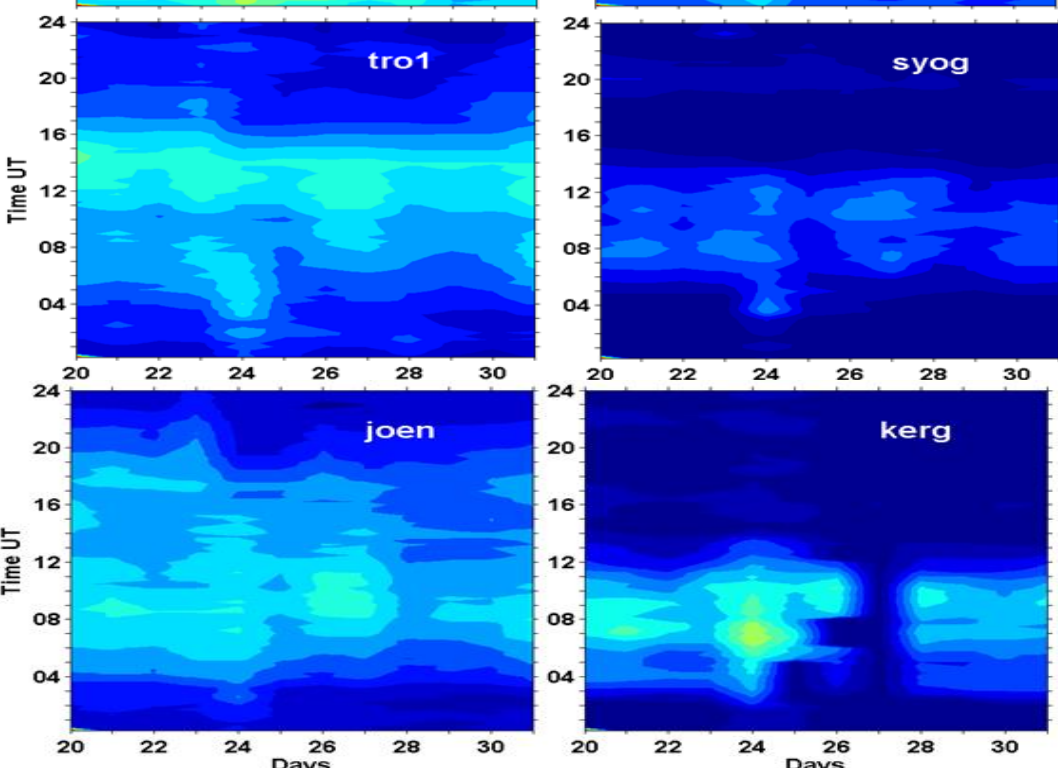

(c)
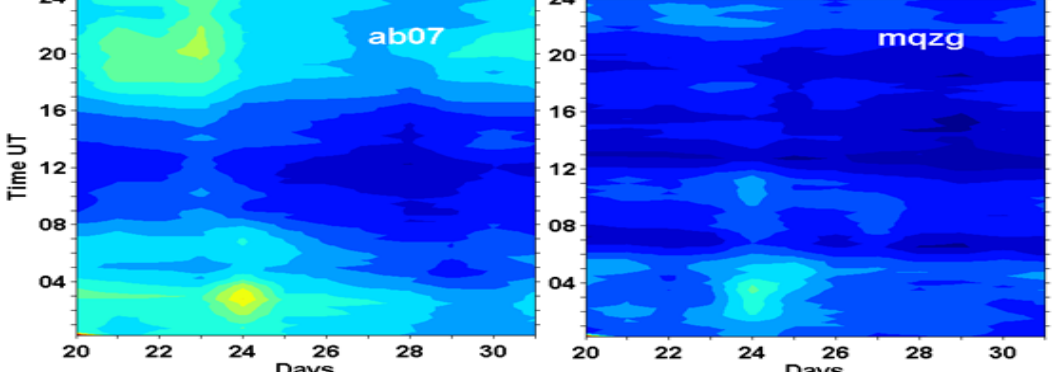

(d)
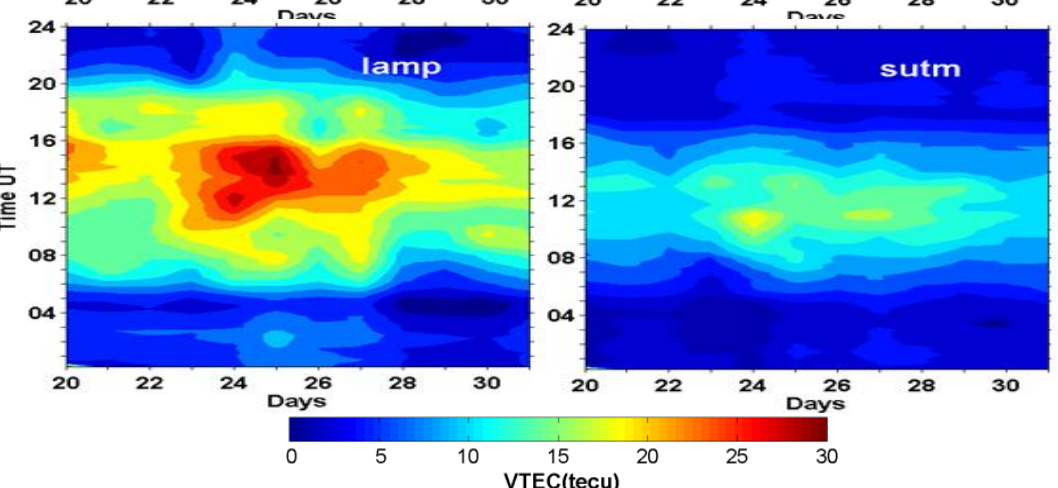

Figure 9 

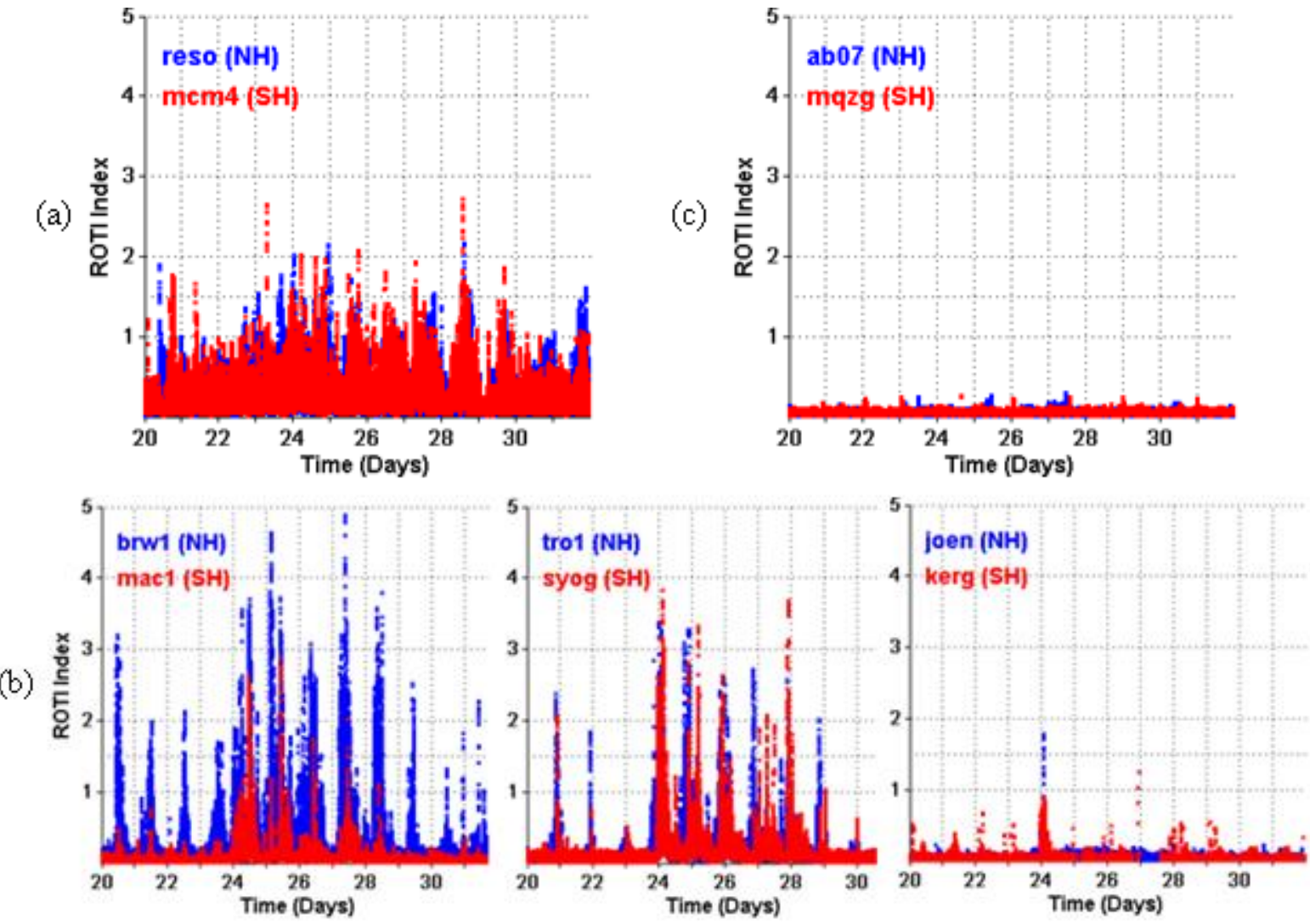

Figure 10 